\title{
Influence of porosity and relative humidity on consolidation of dolostone with calcium hydroxide nanoparticles:
}

\section{Effectiveness assessment with non destructive techniques}

\author{
P.López-Arce $^{\mathrm{a} * *}$, LS.Gomez-Villalba ${ }^{\mathrm{a}}$, L. Pinho ${ }^{\mathrm{b}}$, ME. Fernández-Valle ${ }^{\mathrm{c}}$, M. Álvarez de Buergo ${ }^{\mathrm{a}}$ \\ and R. Fort ${ }^{\mathrm{a}}$ \\ ${ }^{a}$ Group of Applied Petrology to Heritage Conservation, Institute of Economic Geology (CSIC-UCM), \\ Madrid 28040, Spain, plopezar@geo.ucm.es \\ ${ }^{\mathrm{b}}$ Center of Construction Studies, Engineering Faculty, Oporto University, \\ Oporto 4200-465, Portugal
}

${ }^{\mathrm{c}}$ Research Assistance Center, Nuclear Magnetic Resonance (Pluridisciplinar Institute), Complutense University of Madrid (UCM), Madrid 28040, Spain

\begin{abstract}
Slaked lime $\left(\mathrm{Ca}(\mathrm{OH})_{2}\right)$ nanoparticles were exposed at $33 \%$ and $75 \%$ relative humidity ( $\left.\mathrm{RH}\right)$ to consolidate dolostone samples used in historical buildings. Non destructive techniques (NDT) were applied to determine the chemical, morphological, physical and hydric properties of the stone samples, before and after 20 days treatment. Morphological and mineralogical characterisation of the nanoparticles was performed. $75 \% \mathrm{RH}$ favours the consolidation process studied under Environmental Scanning Electron Microscopy (ESEM-EDS), spectrophotometry, capillarity, water absorption under vacuum, ultrasounds velocity, Nuclear Magnetic Resonance (imaging and relaxometry) and Optical Surface Roughness analyses. At $75 \% \mathrm{RH}$ the nanoparticles fill the pores and inter-crystalline dolomite grain contacts but do not favour calcite re-crystallization as it occurs at 33\%RH. The ESEM, XRD and TEM analyses under $75 \% \mathrm{RH}$ reveal the fast transformation of portlandite $\left(\mathrm{Ca}(\mathrm{OH})_{2}\right)$ into vaterite $\left(\mathrm{CaCO}_{3}\right)$, monohydrocalcite $(\mathrm{CaCO} 3)$ and calcite $\left(\mathrm{CaCO}_{3}\right)$, and eventually the physical and hydric properties of the stones significantly improve. New insights are provided for the assessment of consolidation effectiveness of porous carbonate stones with calcium hydroxide nanoparticles under optimum $\mathrm{RH}$ conditions combining several NDT.
\end{abstract}


Keywords: calcium hydroxide nanoparticles; stone; consolidation; humidity; porosity; non destructive techniques

\section{Introduction}

Calcium hydroxide $\left(\mathrm{Ca}(\mathrm{OH})_{2}\right)$ is one of the most interesting products to perform consolidation of calcareous materials such as stone sculptures, monuments or wall paintings. Lime ("lime wash" putty) has been used in the past as an air-hardening binder and in the preparation of the walls for paint application where calcite and silica are the main components of the substratum [1]. When exposed to atmospheric carbon dioxide under moist conditions, calcium hydroxide reacts and converts into calcium carbonate as a result of carbonation. Durability improvement of ancient calcareous bricks from historic buildings has been investigated due to natural re-carbonation of calcium hydroxide inside their porous media $[2,3]$. The low-solubility reaction product has similar physicochemical properties to the ones of the substrate. This fact greatly encourages its application for consolidation purposes and constitutes the main reason to justify the compatibility between the treatment product and substrate materials.

Calcium oxide may be applied in aqueous dispersions, commonly known as lime milk or lime water. These aqueous dispersions present some drawbacks, such as the incomplete conversion of calcium hydroxide into calcium carbonate, post-treatment chromatic alteration and little penetration depth [4]. Some improvements in their properties were identified as critical to the success of consolidation with calcium hydroxide nanoparticles: crystal morphology and size, rate and effect of carbonation on crystal growth and crystallinity degree, control of penetration depth, solution concentrations, additives and solvents, and solubility issues of substrate and products [5].

The use of alcohols as a substitute for water in calcium hydroxide treatments improves the consolidation process [6]. When ethanol or isopropyl alcohol are used as a solvent, dispersions of calcium hydroxide particles show a slower rate of agglomeration (and therefore, slower sedimentation rates) in comparison to aqueous media. This reduces the tendency for a white film to form on surfaces to be consolidated [5]. The method was initially based on the dispersion of micron-sized calcium hydroxide particles [6] but has evolved to the reduction of particle size to submicrometric [7] and nanometric [8] scale. This reduction in particle dimension allows the application of the product on low-porosity substrates $[4,9]$.

The influence of relative humidity (RH) and material's moisture content in the performance of stone consolidation is an important subject in conservation practice. Products such as methyl trimethoxysilane, 
have already been object of study regarding these two variables [10], but their influence is far from being known for materials such as calcium hydroxide nanoparticles. However, the optimal hygrometric conditions for slaked lime storage have been studied [11] and results showed that slaked lime $\left(\mathrm{Ca}(\mathrm{OH})_{2}\right)$, when used as a building material, must be stored in a dry environment (RH below 30\%) and at a temperature between $20-30^{\circ} \mathrm{C}$ in order to avoid carbonation [11,12]. Research carried out by El-Turki et al. [13] on lime mortars has shown that lime pastes exposed to $97 \% \mathrm{RH}$ resulted in a higher carbonation rate and complete carbonation compared to pastes exposed to $65 \% \mathrm{RH}$ where a small amount of calcium hydroxide was detected.

Besides this, a study on the synthesis and carbonation of aqueous and alcoholic lime dispersions showed that greater values of RH allowed obtaining greater carbonation yields. The process seems to be favoured by the addition of a baking soda $\left(\mathrm{NaHCO}_{3}\right)$ solution, resulting in an increase of the effectiveness of the treatment, by completing the carbonation reaction to a conversion factor of 95\% [4]. However, the introduction of sodium salts in the porous system of the stone can produce efflorescences. The application of nanoparticles in different types of solvents [14], or in combination with conventional alkoxysilanes [15] and biomediated processes of calcium carbonate deposition [16] has also been reported.

The compatibility and efficiency of consolidation of decayed artistic calcareous substrates (lime-based wall paintings and architectural limestone surfaces) with nanometric particles of calcium hydroxide (slaked lime) was previously demonstrated by means of superficial area analysis (BET), SEM-EDX and capillarity rise [9] or water imbibition measurements to evaluate penetration depth and surface adhesion of nanolime treatments on Estoril and Pietra Serena stones [4]. In our research, assuming the importance of non-destructive techniques (NDT) to evaluate the performance of protective treatments on cultural heritage, we have applied nuclear magnetic resonance techniques [17], [18] and other NDT such as environmental scanning electron microscopy (ESEM), spectrophotometry, optical surface roughness analyses and ultrasounds propagation velocity to quantify the changes in the physical properties, and water absorption tests to determine the hydric properties, before and after consolidation. Our aim was to evaluate the effectiveness of the consolidation of porous carbonate stone with calcium hydroxide nanoparticles and to determine the optimum humidity conditions through several non-destructive techniques (NDT). 


\section{Materials and methods}

\subsection{Materials and sample preparation}

The nanometric calcium hydroxide dispersion used in this study is a commercial product (Nanorestore ${ }^{\circledR}$ ) developed at the University of Florence (CSGI Consortium) [9]. It is based on a colloidal suspension of nanoparticles of slaked lime $\left(\mathrm{Ca}(\mathrm{OH})_{2}\right)$ dispersed in isopropyl alcohol. The concentration of calcium hydroxide nanoparticles is approximately $1.5 \mathrm{~g} / \mathrm{l}$. The quantity of $1.3 \mathrm{ml}$ of this product with no dilution was deposited on plastic cups and placed at $20^{\circ} \mathrm{C}$ in climatic chambers at $75 \%$ and $33 \%$ RH, with no $\mathrm{CO}_{2}$ flux and no air in circulation, until the product was dried after five days. A second application of $1.3 \mathrm{ml}$ was added again to the containers. The equilibrium relative humidity $\left(\mathrm{RH}_{\mathrm{eq}}\right)$ of saturated salts was used to control the humidity in these small chambers. The RH control chambers containing specific saturated salt solutions were used to keep the humidity constant at $20^{\circ} \mathrm{C}: \mathrm{NaCl}\left(\mathrm{RH}_{\mathrm{eq}} 75 \%\right)$ to simulate a humid environment and $\mathrm{CaCl}_{2}\left(\mathrm{RH}_{\mathrm{eq}} 33 \%\right)$ to simulate a dry environment. After complete evaporation of the solvent in both chambers, a thin film was deposited on the bottom of the cups. The cup of the humid environment showed a homogeneous film, strongly adhered to the surface of the cup, while the cup on the dry environment showed a heterogeneous layout of the film, softly adhered to the bottom of the cup. The product was then analyzed under XRD, TEM and ESEM, after 5, 12 and 20 days of consolidation.

The product was applied to treat a stone sample of dolostone typically used in historic buildings of Madrid (Spain). This stone comes from Redueña, a Cretaceous geologic formation from the North of Madrid. The dolostone specimens of this study have a proportion of calcite around 5\%-10\% and around $95 \%-90 \%$ of dolomite, although the percentages of calcite in the quarries can be higher than $10 \%$. This dolostone is characterized by its cream colour and its high open porosity. Two dolostone specimens $(2.5 \mathrm{x}$ $2.5 \times 1.5 \mathrm{~cm}$ ) were impregnated drop-by-drop with the product with no dilution trough a capillary tube and deposited on the top surface of the specimens. One specimen is a fresh sample from the ancient quarry where the stone was extracted in the past to be broadly used in historical buildings. The other specimen also comes from the ancient quarry, but it was submitted to freezing-thawing cycles artificially accelerated aging tests [19]. The product was applied to both stone specimens, as a consolidating treatment of the specimen submitted to freezing-thawing cycles and as a preventive treatment of the fresh specimen. In a first application, $1.3 \mathrm{ml}$ was applied on their top surfaces. After the application of the product, both specimens, together with two reference plastic containers with the same quantity of product 
$(1.3 \mathrm{ml})$, were introduced in the climatic chambers. The specimen submitted to freezing-thawing cycles (75RH-DOL) was introduced in the humid environment $(75 \% \mathrm{RH})$, since from previous visual observations this seem to be the most favourable condition for a consolidation treatment. While the fresh specimen (33RH-DOL) was introduced in the dry environment (33\% RH), less favourable condition, but considered enough for a preventive treatment. Five days later, a second application of $1.3 \mathrm{ml}$ was applied on the stone specimens. These stone specimens were analyzed before and after 20 days of consolidation.

\subsection{Analytical techniques and experimental procedures}

The stone specimens were analyzed with several NDT, before and after the treatment, in both humid and dry environment, in the following order: Environmental Scanning Electron Microscope (ESEM), spectrophotometer, mobile Optical Surface Roughness (OSR) analyses, propagation of ultrasounds velocity, determination of capillarity, water absorption under vacuum and Nuclear Magnetic Resonance (NMR) to compare the differences in both specimens and to assess the effectiveness of the consolidating product 20 days after the treatment. The nanoparticles were also characterized by X-Ray Diffraction analyses (XRD), Transmission Electron Microscopy (TEM) and Environmental Scanning Electron Microscope (ESEM), after 5, 12 and 20 days.

X-Ray Diffraction analyses (XRD) were performed to analyze the mineralogy and crystallinity of the consolidating product deposited on metallic siliceous holders, after 5, 12 and 20 days. XRD patterns were recorded in an X'Pert Pro MPD Panalytical X'Celerator diffractometer. The sensitivity of this diffractometer allows a faster registration of the XRD patterns and the identification of mineral phases with low crystallinity. The $2 \theta$ range analyzed was $5-80^{\circ}$ with a scan step size of $0.033^{\circ}$ with $200.025 \mathrm{~s} / \mathrm{step}$ in a continuous mode. The working conditions were $45 \mathrm{kV}$ and $40 \mathrm{~mA}$. The mineralogical phases were determined by comparison with the XRD database JCPDS (Joint Committee on Powder Diffraction Standards).

Transmission Electron Microscopy (TEM) analyses were performed to study the shape and the size of the nanoparticles and the structural phases "as deposited" and after 5, 12 and 20 days of consolidation. Samples were prepared by ultrasonic dispersion of this colloidal suspension and then disposed on a carbon coated cupper grid with $3 \mathrm{~mm}$ of diameter. A TEM Jeol JEM operated at $200 \mathrm{KV}$ with electron diffraction mode and energy dispersive X-ray spectroscopy (EDS) Link devices were used for the 
structural and chemical composition control. Digital Micrograph software ${ }^{\mathrm{TM}}$ Gatan inc. was used to measuring the particle size and the interpretation of the electron diffraction patterns.

Environmental Scanning Electron Microscopy (ESEM) was used to study the morphology and distribution of the product on the top and the bottom surfaces (in the corners and in the centre) of the stone specimens before and after 12 and 20 days of consolidation. Digital Micrograph software ${ }^{\mathrm{TM}}$ Gatan inc. was used to the interpretation of ESEM images. Several optical linescans were taken on the images to obtain intensity profiles across porous and non porous surfaces. The length of the optical linescan profiles were between $300 \mu \mathrm{m}$ and $500 \mu \mathrm{m}$ (pixel size $0.363 \mu \mathrm{m} \times 0.363 \mu \mathrm{m}$ ) in the same region, before and after consolidation. The slope, pore diameter and topography changes of the profiles allowed to establish statistic measurements to determine their percentage of reduction or increase as a result of consolidation process. The morphology of the consolidating film deposited on the plastic cups was also observed under ESEM after 5, 12 and 20 days, using a Quanta 200 FEI microscope with Energy Dispersive X-ray Spectroscopy (EDS) (model 7509 Oxford Instrument Analytical, UK) to distinguish dolomite and calcite crystals.

Spectrophotometry was used to measure the chromatic parameters on the surface of the stone specimens before and after 20 days of consolidation, by means of a spectrophotometer (MINOLTA CM-700d), using the Lab system or Lab colour space or CIELAB (Commission Internationale de l'Eclairage CIE 1976), with the following characteristics and operating conditions: 400-700 nm wavelength range, wavelength interval of $10 \mathrm{~nm}$, mean band width of $10 \mathrm{~nm}, 0.01 \%$ resolution, measuring time of 1 second approx., SCI/SCE measuring modes, measuring field ranges from $3 \mathrm{~mm}$ to $11 \mathrm{~mm}$ depending on the selected mask, $\mathrm{L}^{*} \mathrm{a}^{*} \mathrm{~b}^{*}$ which values limit are \pm 1.5 , as well as for indices. Standard illuminant was D50 and observer $10^{\circ}$; measured parameters were $\mathrm{L}^{*}$, which accounts for luminosity, $\mathrm{a}^{*}$ and $\mathrm{b}^{*}$ for coordinates $\left(\mathrm{a}^{*}\right.$ being the red-green parameter and $b^{*}$ the blue-yellow one), and YI for yellow index (measured according to ASTM 313-76). The total colour difference $\Delta \mathrm{E}^{*}$ is also provided as a result of the formula $\Delta \mathrm{E}^{*}=\left(\left(\Delta \mathrm{L}^{*}\right)^{2}\right.$ $\left.+\left(\Delta \mathrm{a}^{*}\right)^{2}+(\Delta \mathrm{b} *)^{2}\right)^{1 / 2}$.

Optical Surface Roughness (OSR) analyses were done, before and after the treatment, on the top and bottom surface of the specimens to evaluate the change in surface roughness due to the application of the consolidating product after 20 days. The thickness of the layer of product deposited on the surface of the sample and the filling of pores can be determined with this technique. The equipment used was a contact- 
free surface profilometer (white light), TRACEiT, patented by Innowep GmbH. It is portable and enables highly precise 3D-topography analysis, at a micro-scale (micrometers). Measuring field is $5 \mathrm{~mm} \times 5 \mathrm{~mm}$, resolution is $2.5 \mu \mathrm{m}(\mathrm{Z}$ axe) and $2.5 \mu \mathrm{m}$ (in $\mathrm{X} / \mathrm{Y}$ axes). Number of data points in $\mathrm{X} / \mathrm{Y}$ axes are 2000.

The OSR analyses included 3D-topography maps $\left(25 \mathrm{~mm}^{2}\right)$ to obtain the average $\mathrm{Ra}, \mathrm{Rq}$ and $\mathrm{Rz}$ roughness parameters and some surface roughness profiles ( $5 \mathrm{~mm}$ length, $\pm 1 \mathrm{~mm}$ height) measured on the top and bottom surfaces of the stone specimens. The cut off $(\lambda \mathrm{c})$ used for calculations is $0.80 \mathrm{~mm}$.

The roughness parameters analyzed were calculated by the software and defined as stipulated in DIN EN ISO 4287 standard [20]: (i) $\mathrm{Ra}$ is the arithmetic mean of the absolute values of profile deviations from the mean line; (ii) $\mathrm{Rq}$ represents the root square deviation of the assessed profile, also known as RMS (Root Mean Square roughness) and (iii) $\mathrm{Rz}$ is the sum of the vertical distances between the five highest peaks and the five deepest valleys within the sampling length.

Propagation of ultrasounds velocity was measured before and after 20 days of treatment to evaluate the increase in durability and the distribution of the consolidating product, for $\mathrm{Vp}$ (P-wave velocity) that is related to effective porosity. P-wave propagation time was measured to a precision of $0.1 \mu \mathrm{s}$ with a PUNDIT CNS Electronics instrument. Standard recommendations were followed, with some differences respecting: (i) specimen shape and size (specimens $2.5 \times 2.5 \times 1.5 \mathrm{~cm}$ sides, $\mathrm{X}, \mathrm{Y}$ and $\mathrm{Z}$ axes, instead of the prismatic specimens prescribed in the Spanish and European standard UNE-EN 14579: 2005 [21] on sound speed propagation); and (ii), the frequency of the transducers used, which was $1 \mathrm{MHz}$. The diameter of the flat contact area on these transducers was $11.82 \mathrm{~mm}$. The bond between the transducers and the surface of the specimens was secured with a water and carboxymethylcellulose paste (Sichozell Kleister, Henkel). Measurements were taken in direct transmission/reception mode, across opposite parallel sides of the cubic specimens in all three spatial directions.

Water absorption by capillarity was carried out to study the hydric behaviour through the stone before and after the 20 days treatment, using a continuous data-recording ACUASOR, designed by the Physics and Chemistry Department at the University of Cadiz (Spain). The balance device was linked to a computer which automatically records weight gain in the tested specimen at specified intervals (every (1/f) seconds ${ }^{1 / 2}$, in the current study $\mathrm{f}=2$ ). It allows automatic monitoring of the water uptake by the sample when its lower surface is in contact with the water reservoir. The continuous absorption method permits an extremely accurate characterisation of building materials with high absorption rates. 
Water absorption under vacuum was performed to determine the bulk density, open porosity and to quantify the amount of water absorbed by the specimens once they reach saturation, as described in the Spanish and European standard UNE-EN 1936: 1999 [22] on natural stone test methods. Although this standard has now been replaced by UNE EN 1936: 2007, the 1999 edition was in effect when the trials were begun and therefore was the one used throughout the experiment. The test was done before and after the 20 days treatment, and just before the NMR analyses in order to get the samples fully saturated with water.

Nuclear Magnetic Resonance (NMR) was measured before and after the 20 days treatment to observe and to quantify the location and distribution of water and consolidating product inside the pores of the stone specimens. It was also used to evaluate the depth of penetration of the consolidating product inside the stone. Magnetic Resonance Imaging (MRI) and Relaxometry experiments were done after the water absorption under vacuum experiments. The samples were covered with parafilm to avoid water evaporation during NMR experiments. Water proton spin-lattice (T1) and spin-spin (T2) relaxation data were evaluated to study the effect induced on the stone porous structure by the presence of the consolidation product.

MRI and relaxometry experiments were performed using a BIOSPEC BMT 47/40 (Bruker, Ettlingen, Germany) spectrometer, operating at $4.7 \mathrm{~T}$. Magnetic field gradients for imaging in the three orthogonal directions were generated by a $12 \mathrm{~cm}$ actively shielded gradient set capable of reaching $200 \mathrm{mT} / \mathrm{m}$. Individual specimens $(2.5 \times 2.5 \times 1.5 \mathrm{~cm}$ sides) were placed in a radio frequency birdcage coil with an inner diameter of $7 \mathrm{~cm}$. For the MRI experiments a first global shimming was performed and then three scout spin-echo experiments in axial, sagital and coronal direction were acquired. The acquisition parameters for these images were: repetition time $\mathrm{TR}=200 \mathrm{~ms}$, echo time $\mathrm{TE}=10 \mathrm{~ms}$, field of view $\mathrm{FOV}=10 \mathrm{~cm}$, slice thickness SLTH=5mm, matrix size $=128 \times 128$ and number of acquisition NEX=1. Then four T1 weighted axial spin-echo $(\mathrm{TR} / \mathrm{TE}=700 / 5 \mathrm{~ms})$ images were acquired. For T2 relaxation time measurements 20 echoes of three coronal slices using a spin-echo sequence were acquired. For these experiments the TR was $2000 \mathrm{~ms}$, the echo time TE varied from $5 \mathrm{~ms}$ to $100 \mathrm{~ms}$, FOV was $4 \mathrm{x} 4 \mathrm{~cm}^{2}$ and the matrix size was $128 \times 128$. Six slices of $2.5 \mathrm{~mm}$ were registered. The signal was averaged 6 times. T1 relaxation time measurements were conducted on the same slices using a spin-echo sequence. Separate images were acquired at seven different recovery times. TR varied from $250 \mathrm{~ms}$ to $6000 \mathrm{~ms}$ and the TE was $5 \mathrm{~ms}$. From 
these sequences, $\mathrm{T} 1$ and $\mathrm{T} 2$ values at nine different Region of Interest (ROI) and T1 and T2 maps were calculated using ParaVision 3.0.1 package (Bruker, Ettligen, Germany). Signal Intensity as the signal at equilibrium magnetization was also obtained. The data was then processed in order to reduce the information by grouping the data with similar values from three areas and from the top to the bottom of the specimens. Then the MRI information is given for three slices in $\mathrm{Z}$ axes with a thickness of $0.5 \mathrm{~cm}$ height divided in three areas of $2.2 \mathrm{~cm}^{2}$. So, we have the MRI data of each specimen from the top to the bottom to observe the deep penetration of the consolidating product and its location and distribution through different areas of the specimen.

Relaxometry experiments were performed on the same specimens just after the imaging experiments without any manipulation of the samples. These measurements correspond to spatially non-resolved data and they were used to obtain the quasicontinuous distribution curves using the UpenWin 1.01 program [23]. For T1, measurements 200 inversion times, varying from $10 \mathrm{~ms}$ to $2000 \mathrm{~ms}$, of a standard InversionRecovery spin sequence was acquired. For T2 a CPMG sequence was used. 200 echoes with TE $=800 \mu \mathrm{s}$ were registered.

\section{Results and discussion}

\subsection{Characterisation of nanoparticles}

\subsubsection{X-Ray Diffraction analyses (XRD)}

Fig. 1 displays the XRD patterns of the consolidating product after 5, 12 and 20 days of consolidation in high and low humidity conditions (75\%RH and 33\%RH, respectively). Fig.1a and Fig.1b show the results of the XRD data obtained after 5 days of consolidation. The XRD patterns show a well defined crystalline

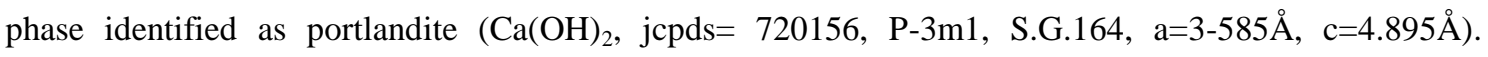
Differences in the intensity of the peaks reveal better defined diffraction maximums in the sample crystallized in low humidity conditions (Fig.1b) Fig. 1c and Fig. 1d show the XRD results after 12 days of consolidation. In high humidity conditions (Fig.1c) a very broad diffractogram pattern is obtained where the development of the vaterite phase $\left(\mu \mathrm{e}-\mathrm{CaCO}_{3}\right.$, jcpds=33-0268, P63/mmc, $\mathrm{SG}=194, \mathrm{a}=7.147 \AA$, $\mathrm{c}=16.91 \AA$ ) can be identified. Vaterite is associated to the presence of monohydrocalcite $\mathrm{CaCO}_{3} \cdot \mathrm{H}_{2} \mathrm{O}$ (jcpds=29-0306) and a small amount of calcite $\mathrm{CaCO} 3$ (jcpds=01-086-2342 R-3c, SG=167)). In low humidity conditions (Fig. 1d) the XRD data reveals a better definition of the intensity maximums associated to portlandite phase $\left(\mathrm{Ca}(\mathrm{OH})_{2}\right.$ and the presence of a small amount of calcite, $\mathrm{CaCO}_{3}$ (jcpds= 
01-086-2342), R-3c, SG=167) Fig.1e and Fig.1f display the XRD data after 20 days. The high humidity conditions (Fig.1e) have favoured the crystallization of the vaterite and monohydrocalcite phases. Additionally, small peaks of calcite have been identified. In low humidity conditions (Fig.1f) portlandite $\left(\mathrm{Ca}(\mathrm{OH})_{2}\right.$ is present together with calcite $\left(\mathrm{CaCO}_{3}\right)$. These XRD analyses reveal the fast transformation of portlandite into vaterite (metastable $\left.\mathrm{CaCO}_{3}\right)$, monohydrocalcite $\left(\mathrm{CaCO}_{3} \cdot \mathrm{H}_{2} \mathrm{O}\right)$ and calcite $\left(\mathrm{CaCO}_{3}\right)$ in high humidity conditions $(75 \% \mathrm{RH})$ and mainly the presence of only portlandite $\mathrm{Ca}(\mathrm{OH})_{2}$ with a small amount of calcite in low humidity conditions $(33 \% \mathrm{RH})$ after 20 days of consolidation.

\subsubsection{Transmission Electron Microscopy (TEM)}

Fig. 2 shows the TEM image and the electron diffraction results obtained on the product "as deposited". The TEM image in bright field mode (Fig.2a) shows agglomerates of short prismatic and hexagonal habit crystals of portlandite with particle size of $59.4 \mathrm{~nm} \pm 23$. Fig. $2 \mathrm{~b}$ shows the selected area electron diffraction pattern (saedp) of nanoparticles after 5 days in high humidity conditions $(\mathrm{RH}=75 \%)$. The polycrystalline character is clearly evident in the rings pattern which is indexed according to the portlandite phase previously identified by XRD. In Fig.2c the saedp obtained in the same sample shows other phase with a good grade of crystallinity where the spots are indexed according to the d- $h k l$ distances of vaterite phase according to the hexagonal structure with P63/mmc symmetry [24]. Chemical analyses performed by TEM-EDS and electron diffraction results confirm the presence of portlandite and vaterite phases at 5 days in high humidity conditions. The latter phase was not detected by XRD. The measurements of the particle size obtained from the TEM images indicate that in high humidity conditions there is a bimodal and trimodal distribution: after 5 days of consolidation there are two groups of particle size whose longest axes are $127 \mathrm{~nm} \pm 53$ and $1409 \mathrm{~nm} \pm 410$; after 12 days of consolidation there are three groups of particle size which longest axes are $103.9 \mathrm{~nm} \pm 42,344 \mathrm{~nm} \pm 36$ and $2258 \mathrm{~nm} \pm 342$; after 20 days of consolidation there are three groups of particle size which longest axes are $62.3 \mathrm{~nm} \pm 17,213 \mathrm{~nm} \pm 185$ and $2298 \mathrm{~nm} \pm 154$. In low humidity conditions there is only a bimodal distribution: after 5 days of consolidation there are two groups of particle size which longest axes are $52.6 \mathrm{~nm} \pm 16$ and $167 \mathrm{~nm} \pm 60$; after 12 days of consolidation the longest axes of the particles are $64.2 \mathrm{~nm} \pm 15$ and $193 \mathrm{~nm} \pm 22$; after 20 days of consolidation the longest axes of the particles are $62.2 \mathrm{~nm} \pm 22$ and $307 \mathrm{~nm} \pm 143$. These results are indicating the growth of portlandite crystals and the beginning of the carbonation process with the growth of new particles of vaterite. There is a faster growth rate and larger particle sizes in high RH conditions 
compared to low RH conditions. According to TEM and XRD results vaterite is favoring the formation of calcite phase. Even although vaterite is a metastable phase it can become stable with low thermal treatments at $27^{\circ} \mathrm{C}[24]$.

\subsubsection{Environmental Scanning Electron Microscopy (ESEM)}

ESEM showed the morphology and distribution of the consolidating film of calcium hydroxide nanoparticles deposited on the plastic cups on humid and dry environment (Fig.3), after 5 days (Fig.3a and 3b), 12 days (Fig.3c and 3d) and after 20 days (Fig.3e and 3f). There are significant differences between the crystallization of the nanoparticles in the different environments. In the humid environment the nanoparticles display needle-shaped crystals homogeneously distributed and embedded in a microcrystalline matrix which amount increases with the consolidation time. According to the XRD and TEM results the observed crystals might correspond with the portlandite and vaterite phases. In the dry environment the nanoparticles heterogeneously distributed as aggregates of anhedral crystals, which size and amount increase with the consolidation time (5, 12 and 20 days).

\subsection{Characterisation of stone specimens}

\subsubsection{Environmental Scanning Electron Microscopy with Energy Dispersive X-ray (ESEM-EDS)}

ESEM showed the differences between the fresh stone specimen (specimen 33RH-Dol) and the specimen submitted to freezing-thawing cycles (specimen 75RH-DOL). Since both specimens come from the same dolostone sample, the calcite vs. dolomite proportion is about the same in both specimens $(90-95 \%$ dolomite crystals approx.). Dolomite and calcite crystals in the stone specimens were distinguished by

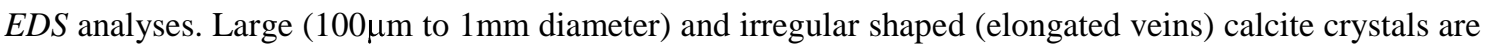
embedded in a microcrystalline dolomite matrix with small $(30 \mu \mathrm{m}$ to $100 \mu \mathrm{m}$ diameter) rhombic and idiomorphic crystals. These dolomite crystals display intra-crystalline micro-pores in high proportion (with pore sizes between $1 \mu \mathrm{m}$ to $10 \mu \mathrm{m}$ diameter), medium proportion (with pore sizes between $1 \mu \mathrm{m}$ to $5 \mu \mathrm{m}$ diameter) and crystals with no pores (Fig.4a). The quantity of microcrystals with a medium proportion of micro-pores is higher than the quantity of microcrystals with high proportion of micropores, followed by those crystals with no pores. EDS analyses were performed on these dolomite crystals. The EDS results showed that only calcium (68.47\% weight) and magnesium (31.53\% weight) are present in the dolomite crystals with no pores. However, besides calcium $(\mathrm{Ca})$ and magnesium $(\mathrm{Mg})$, aluminium (Al) and silicon ( $\mathrm{Si}$ ) are also present in the crystals with high and medium proportion of pores. The 
weight percentage of these elements in the dolomite crystals with medium proportion of pores is: $\mathrm{Ca}$ $62.80 \%, \mathrm{Mg} 35.58 \%$; Si $0.96 \%$ and $\mathrm{Al} 0.65 \%$ and in the dolomite crystals with high proportion of pores: $\mathrm{Ca} 69.70 \%, \mathrm{Mg} 28.25 \%$; Si $1.30 \%$ and $\mathrm{Al} 0.76 \%$. This suggests the mobility and solubility of $\mathrm{Mg}$ and $\mathrm{Ca}$ ions and the lost of $\mathrm{Mg}$ from the dolomite crystals giving raise to the observed porosity.

The microcrystalline matrix of dolomite crystals displays inter-crystalline small pores $(30 \mu \mathrm{m}$ to $70 \mu \mathrm{m}$ diameter) and large pores $(100 \mu \mathrm{m}$ to $500 \mu \mathrm{m}$ diameter). All these characteristics are common in the centre of the top and bottom surfaces of both stone specimens. The main difference between both specimens is related to the proportion of inter-crystalline pores in the matrix with a diameter of circa $100 \mu \mathrm{m}$ and the presence of fissures that is higher in the specimen 75 RH-DOL. This difference is even higher in the corners of the specimens. After 20 days in high humidity conditions (specimen 75RH-DOL) there are recrystallized edges of calcite crystals, some local dissolution along the cleavage surfaces and local removing of dolomite crystals. The consolidation action is more evident in the previously fractured grains, inside the pores and in the inter-crystalline dolomite grain contacts (Fig.4). After 20 days in low humidity conditions (specimen 33RH-DOL) the nanoparticles have improved the crystallinity of calcite, however the crystallinity of dolomite gets worse, producing the dissolution, fracture and local removing of some crystals. The consolidating product superficially fills the pores, covering the crystal surfaces (Fig.5). Dolomite crystals with medium quantity of intra-crystalline porosity ( $1 \mu \mathrm{m}$ to $5 \mu \mathrm{m})$ are more affected by dissolution and fracturing than those crystals with higher and lower quantities of intracrystalline pores. EDS analyses showed that these crystals have lower amount of $\mathrm{Ca}$ and higher amount of Mg compared to the other dolomite crystals. The nanoparticles on one hand, are dissolving and fracturing the dolomite $\left(\mathrm{CaMg}\left(\mathrm{CO}_{3}\right)_{2}\right)$ crystals (with less concentration of calcium and more concentration of magnesium) and by other hand, they are favouring the re-crystallization of calcite $\left(\mathrm{CaCO}_{3}\right)$ crystals (with only calcium and no magnesium). In the corners of the specimens, where there is less amount of consolidating product, less deterioration is identified over the dolomite crystals with respect to the deterioration found in the centre of the specimens. The dissolution of dolomite crystals is especially evident in the specimen 33RH-DOL (Fig.5a and Fig.5b). In Fig.4 and Fig.5 the ESEM images with the optical linescan intensity profiles taken on these images of the stone specimens before and after consolidation are shown. The profiles obtained over dolomite crystals on specimen 75RH-DOL (Fig.4) show a reduction in the diameter and the height of the pores due to the filling of pores. Fig.4a and Fig.4b 
show the reduction of pore diameters from $28.02 \mu \mathrm{m}$ and $29.47 \mu \mathrm{m}$ down to $10.91 \mu \mathrm{m}$ ( $61 \%$ reduction) and $26.91 \mu \mathrm{m}$ ( $9 \%$ reduction), respectively. Additionally, there is an increase in the pore height between $30 \mu \mathrm{m}$ to $60 \mu \mathrm{m}$. In Fig.4, ESEM images show some dissolution of the dolomite crystals but also the filling of pores and between the inter-crystalline contacts. The optical linescan intensity profiles taken over dolomite crystals on the specimen 33RH-DOL show the decrease of pore diameters from $112.14 \mu \mathrm{m}$ and $27.12 \mu \mathrm{m}$ down to $48.20 \mu \mathrm{m}$ and $24.10 \mu \mathrm{m}$, respectively (Fig.5a. and Fig.5b) identified by the contrast in the images. There is a reduction in the pore diameter (69\% and $11 \%$, respectively) and an increase in the height of the pores between $30 \mu \mathrm{m}$ to $60 \mu \mathrm{m}$. There is also a significant dissolution of the dolomite crystals (Dol) and re-crystallization of calcite crystals $(\mathrm{Cc})$. The profiles obtained in areas with higher amount of calcite (Fig 5c and Fig. 5d) show the significant re-crystallization along its cleavage planes. The size reduction (10\%) of a pore from $65.56 \mu \mathrm{m}$ (Fig. $5 \mathrm{c}$ ) down to $58.76 \mu \mathrm{m}$ (Fig. $5 \mathrm{~d}$ ) after the filling with the nanoparticles can be also observed.

\subsubsection{Spectrophotometry}

Table 1 displays the colour variations of the treated stone surfaces. For the tested treatment the most important contribution came from $\Delta \mathrm{b}^{*}$, followed by $\Delta \mathrm{L}^{*}$. On both specimens a negative yellowing effect was produced, as shown by the $\Delta \mathrm{YI}$ value. This result, together with the positive value of $\Delta \mathrm{L}^{*}$ (luminosity), may be interpreted as a slight whitening effect on the dolostone after treatment. The specimen $75 \mathrm{RH}-\mathrm{DOL}$ has a lower colour difference $\left(\Delta \mathrm{E}^{*}\right)$ compared to specimen $33 \mathrm{RH}-\mathrm{DOL}$, since $\Delta \mathrm{E}^{*}$ value is less than 3 in the former specimen and less than 5 in the latter. However, considering compatibility criteria, indicators available in literature show that when $\Delta \mathrm{E}^{*}$ (total colour difference) is less than 3 the risk of incompatibility is 0 and when $\Delta \mathrm{E}^{*}$ is between 3 and 5 the risk is 5 (in a 5 to 10 scale) [25].

\subsubsection{Optical Surface Roughness (OSR)}

Table 2 shows the surface roughness parameters obtained on the $25 \mathrm{~mm}^{2}$ area (3D height or topographic map) and on 5mm long roughness profiles, measured on the top and the bottom of the specimens through porous and non porous surfaces. The topographic maps and the profiles are based on the $\mathrm{Ra}, \mathrm{Rq}$ and $\mathrm{Rz}$ roughness parameters (in $\mu \mathrm{m}$ ). These parameters do not show relevant changes as a result of the consolidation, except for Ra on the top of the specimen 33RH-DOL (Fig.6 and Table 2). In this specimen the nanoparticles have slightly modified $\mathrm{Rq}$ and $\mathrm{Rz}$ roughness parameters but $\mathrm{Ra}$ significantly decreases 
$(112 \%)$ as a result of a deposition layer (45 mm thick approx.) of nanoparticles, which gives rise to a smoother surface (Fig.7). In the porous profiles measured on the top of this specimen, Ra and Rz increase $6 \%$ and $4 \%$, respectively (by dissolution of some dolomite crystals); in non porous profiles, $\mathrm{Ra}$ and $\mathrm{Rz}$ decrease $11 \%$ and $9 \%$, respectively (Table 2). In the bottom of this specimen (both across porous and non porous profiles) $\mathrm{Ra}$ and $\mathrm{Rz}$ decrease $16 \%$ and between $9 \%$ and $19 \%$, respectively. The decrease in these parameters is due to calcite re-crystallization and due to the smoother surfaces caused by the consolidating product. In the specimen 75RH-DOL, the nanoparticles have slightly modified $\mathrm{Ra}, \mathrm{Rq}$ and $\mathrm{Rz}$ (on the average area $25 \mathrm{~mm}^{2}$ ). However, these parameters on the top of this specimen significantly change when they are obtained on surface roughness profiles across porous (Ra and Rz increase $13 \%$ and $6 \%$, respectively, due to dissolution of some dolomite crystals) or in non porous surfaces ( $\mathrm{Ra}$ and $\mathrm{Rz}$ decrease $13 \%$ and $5 \%$, respectively, as the consolidating product gives rise to smoother surfaces). In the bottom of this specimen, both in porous and non porous profiles, Ra and $\mathrm{Rz}$ decrease. In porous profiles, $\mathrm{Ra}$ and $\mathrm{Rz}$ decrease $3 \%$ and $10 \%$ respectively, and in non porous profiles, $\mathrm{Ra}$ and $\mathrm{Rz}$ decrease $99 \%$ and $84 \%$, respectively. These results show that the consolidating product has affected the top and the bottom surfaces of the specimens, in general decreasing the surface roughness parameters. Fig.7 shows four representative profiles obtained from the specimens subjected to high humidity (Fig.7a) and low humidity conditions (Fig.7b). A more detailed study on the changes of pore diameters was made on the surface roughness profiles. On the top surface of the specimen in high humidity conditions (specimen 75RHDOL), there is almost no reduction of pore diameters of $0.3 \mathrm{~mm}$ but there is an increase of pore height from $20 \mu \mathrm{m}$ up to $40 \mu \mathrm{m}$. In the bottom of this specimen there is an average reduction of pore diameter from $0.3 \mathrm{~mm}$ down to $0.1 \mathrm{~mm}$ but there is no change in the pore height. On the top surface of the specimen in low humidity conditions (specimen 33RH-DOL) there is almost no reduction of pore diameters of around $0.3 \mathrm{~mm}$ but there is an increase of pore height from $20 \mu \mathrm{m}$ up to $50 \mu \mathrm{m}$ (this can be related to the dissolution of dolomite crystals surrounding the pores as it was observed under ESEM and also in the 3D topographic map (Fig.6)). In the bottom of this specimen there is only a slight reduction in the pore diameter from $0.4 \mathrm{~mm}$ down to $0.3 \mathrm{~mm}$ and a slight reduction in the pore height from $30 \mu \mathrm{m}$ down to $20 \mu \mathrm{m}$. The modification in the pores morphology is manifested in the filling of pore valleys and changes in the shape of the profiles (Fig.7). There is only a slight reduction in the pore diameter of larger pores (millimetre size) in both specimens; the nanoparticles were deposited on the surface of the stones giving 
rise to smoother areas, and in the slopes of the pores resulting on increasing the height of the pores, especially in the specimen 33RH-DOL (Fig.6).

\subsubsection{Propagation of ultrasounds velocity}

Ultrasounds velocity was measured before and after the consolidation treatment in both specimens (Table 3). Before consolidation, the average velocity across the 3 spatial axes of both specimens is $22 \%$ higher for the specimen 33RH-DOL $(2674 \mathrm{~m} / \mathrm{s})$ compared to the specimen $75 \mathrm{RH}-\mathrm{DOL}(2187 \mathrm{~m} / \mathrm{s})$. This difference is due to the higher porosity and the fissures generated by the freezing-thawing cycles in the specimen 75RH-DOL, since higher values of ultrasounds velocity is related to more stone cohesion. After consolidation of specimen 75RH-DOL the average velocity increases from $2187 \mathrm{~m} / \mathrm{s}$ up to $2585 \mathrm{~m} / \mathrm{s}$. However, after consolidation of specimen 33RH-DOL the average velocity only increases from $2674 \mathrm{~m} / \mathrm{s}$ up to $2747 \mathrm{~m} / \mathrm{s}$. Therefore the average variation velocity $\Delta \mathrm{Vp}(\%)$ is much higher for the former specimen compared to the latter ( $18 \%$ and $3 \%$, respectively). The increase in the ultrasounds velocity takes place along the 3 axes of both specimens, however for specimen 33RH-DOL this increase is only significant along $\mathrm{X}$ axe; the velocity increase in the other two axes is very low since the values remain almost constant (Table 3). However, the increase in ultrasounds velocity for specimen 75RH-DOL is more significant and very similar along the three spatial directions (increase of $400 \mathrm{~m} / \mathrm{s}$ approx.). This can be related to the higher reduction in porosity and the better and more homogeneous distribution of the consolidating product in the specimen 75RH-DOL compared to 33RH-DOL. The highest initial porosity of this specimen could be the cause of a better distribution of the consolidating product inside its pores (the same quantity of product was applied in both specimens). Therefore, after the treatment, the ultrasounds velocity increase, and besides the porosity, the influence of higher humidity during consolidation could have allowed a better cohesion of the consolidating product.

\subsubsection{Water absorption by capillarity}

The capillary imbibition kinetics of the two specimens of dolostone, before and after consolidation, is displayed in Fig. 8. The first part of each curve defines the capillary water absorption and the second part defines the saturation. The slope of the curve during capillary absorption is the capillary absorption coefficient, $C$ (Table 4). This coefficient, $C$, is closely related to pore structure by the pore radius and the porosity. Smaller pore radius and smaller connected porosity values give lower coefficients $(C)$ and slow water transport [26]. Before consolidation, both curves (Table 4) are very similar, although the 
coefficient, $C$, is $40 \%$ higher for specimen $75 \mathrm{RH}-\mathrm{DOL}\left(198.3 \mathrm{~g} / \mathrm{m}^{2} \cdot \mathrm{s}^{0.5}\right)$ compared to the specimen $33 \mathrm{RH}$ DOL $\left(141.5 \mathrm{~g} / \mathrm{m}^{2} \cdot \mathrm{s}^{0.5}\right)$. In both specimens $C$ decreases as a result of the treatment. Table 4 shows that the decrease is higher in the specimen 75RH-DOL. After the treatment, $C$ decreases $16 \%$ (from 141.5 $\mathrm{g} / \mathrm{m}^{2} \cdot \mathrm{s}^{0.5}$ to $122.4 \mathrm{~g} / \mathrm{m}^{2} \cdot \mathrm{s}^{0.5}$ ) in the specimen 33RH-DOL. However, after treatment, $C$ decreases $83 \%$ (from $198.3 \mathrm{~g} / \mathrm{m}^{2} \cdot \mathrm{s}^{0.5}$ to $108.3 \mathrm{~g} / \mathrm{m}^{2} \cdot \mathrm{s}^{0.5}$ ) in specimen 75RH-DOL giving rise a $C$ value $13 \%$ lower than the $C$ value in the specimen 33RH-DOL. Before treatment, the water absorption by capillarity of both specimens is $0.9 \mathrm{~g}$ approx. and after treatment this value reaches $1.5 \mathrm{~g}$ and $1.0 \mathrm{~g}$, respectively (Table 4). Therefore, after treatment, $C$ decrease in both specimens, however water absorption by capillarity increase. These results are in agreement with the values obtained in the propagation of ultrasounds velocity. Before the treatment specimen 33RH-DOL has higher values of ultrasounds velocity and lower $C$ values, since specimen $75 \mathrm{RH}-\mathrm{DOL}$ was artificially weathered by freezing-thawing cycles and it has less cohesion and larger pores and fissures due to the aging compared to 33RH-DOL. However, after treatment the increase in ultrasounds velocity $(18 \%)$ and decrease in $C(83 \%)$ is much higher in the specimen 75RH-DOL. This can be explained by a better cohesion of the specimen in humid conditions (specimen with higher and larger pores) favouring the reduction of number of pores and pore sizes, fissures and distances between crystal contacts and giving rise to a smaller connected porosity, slower water transport and hence lower capillary absorption coefficient.

\subsubsection{Water absorption under vacuum}

These results show that the apparent density is very similar before and after treatment in both specimens (Table 5). After treatment, there is a decrease in the open porosity and saturation values in both specimens, although the decrease is higher in specimen 75RH-DOL (decrease from $19.0 \%$ to $18.2 \%$ open porosity and from $8.3 \%$ to $7.8 \%$ saturation) than in specimen $33 \mathrm{RH}-\mathrm{DOL}$ (decrease from $16.6 \%$ to $16.3 \%$ open porosity and from $7.1 \%$ to $6.9 \%$ saturation). Before treatment, the saturation reached through water absorption by capillarity (Fig.8 and Table 4) in both specimens is slightly lower than the saturation obtained trough water absorption under vacuum ( $1.3 \mathrm{~g}$ by capillarity and $1.6 \mathrm{~g}$ by vacuum for $33 \mathrm{RH}-\mathrm{DOL}$ and $1.4 \mathrm{~g}$ by capillarity and $1.9 \mathrm{~g}$ by vacuum for $75 \mathrm{RH}-\mathrm{DOL})$. After treatment, the saturation reached by capillarity in both samples reaches the saturation value obtained under vacuum $1.6 \mathrm{~g}$ and $1.8 \mathrm{~g}$, respectively. Although the water absorption by capillarity slightly increases in both specimens the 
capillarity coefficient (i.e. absorption rate) and the total amount of water that the specimens are able to absorb (i.e. water saturation) decrease after treatment.

\subsubsection{Nuclear Magnetic Resonance (NMR): Magnetic Resonance Imaging (MRI)}

The results of MRI obtained for the three slices cut along the $\mathrm{Z}$ axe (top, centre and bottom) are shown in Table 6 and Table 7. Before the treatment, these results show lower and more homogeneous values of relaxation times $\mathrm{T} 1$ and $\mathrm{T} 2$ in the specimen 33RH-DOL compared to 75RH-DOL. Higher T1 and T2 values are related with larger pores $[27,28]$. If before treatment, MRI results show lower T1 and T2 values for specimen 33RH-DOL, this would mean the presence of smaller pores in this specimen compared to 75RH-DOL. Specimen 33RH-DOL shows that T1 and T2 values increase from area 1 to area 3 but these values are very similar from the top to the bottom of the specimen (Table 7). After treatment, $\mathrm{T} 1$ and $\mathrm{T} 2$ relaxation times in this specimen decrease in all the areas and depths. This means the presence of pores with similar size before treatment and a reduction of pore sizes after consolidation. Before treatment, specimen 75RH-DOL shows that $\mathrm{T} 1$ and $\mathrm{T} 2$ values decrease from area 1 to area 3 of the specimen and from the top to the bottom of the specimen (Table 6). After treatment of this specimen, $\mathrm{T} 1$ and $\mathrm{T} 2$ relaxation times generally decrease but not in all the areas and depths (only in the top and the center of the specimen). The bottom of this specimen shows a slight increase and decrease in $\mathrm{T} 1$ and $\mathrm{T} 2$ values, respectively. The locations with more changes are the center and the top of the specimen, except the top of area 1, area with the highest values of T1 and T2 (larger pores) in the specimen. This means that before treatment there are different pore sizes that decrease from the top to the bottom of the specimen and after treatment there is a reduction of the size of the pores located in the top and center of the specimen. T1 values of area 1 remain constant in the top and increase (3\%) in the bottom; it seems that the consolidating product passed through the larger pores of the top of the specimen because it could not fill them and it was then deposited on the top of the other two areas and in the center of the specimen. The heterogeneity of $\mathrm{T} 1$ and $\mathrm{T} 2$ values in specimen $75 \mathrm{RH}-\mathrm{DOL}$ allow to have comparable areas related with some areas of specimen 33RH-DOL, with similar T1, T2 and PD (Proton density or signal intensity) values in both specimens before the treatment. This can be observed in the area 3 from the top to the bottom of the specimens (Table 6 and Table 7).

In this area 3 and in both specimens, $\mathrm{T} 1$ and $\mathrm{T} 2$ relaxation times decrease after treatment. In the top of area 3 of the specimens, the decrease in T1 value is higher for the specimen 75RH-DOL (16\%) compared 
to the decrease for specimen 33RH-DOL (9\%). However, the decrease in T2 value is higher for the specimen 33RH-DOL (25\%) compared to the decrease for specimen 75RH-DOL (20\%). In the center of both specimens $\mathrm{T} 1$ and $\mathrm{T} 2$ values decrease. The relaxation times in the bottom of the specimens after treatment are quite different for both samples. T1 and T2 slightly decrease in specimen 33RH-DOL but these parameters remain almost constant for the specimen 75RH-DOL.

Before treatment, T2 values in this area 3 are slightly higher in 33RH-DOL compared to 75RH-DOL, however after treatment, T2 values in both specimens decrease and come close to each other. The decrease in $\mathrm{T} 1$ and $\mathrm{T} 2$ parameter means a decrease in the pore sizes or the generation of smaller pores [28], especially in specimen 75RH-DOL.

The signal intensity is heterogeneous in both specimens, but it is slightly lower for 75RH-DOL compared to 33RH-DOL. The signal intensity slightly increases in both specimens after treatment, but we know from the hydric measurements that water saturation after treatment decrease. The increase in signal intensity could be related to the effect of the consolidating product, thus higher signal intensity would mean higher density of the consolidating product. The development of hydrated carbonates (monohydrocalcite) at $75 \% \mathrm{RH}$ would also increase the signal density of the samples after treatment. If we introduce the same amount of consolidating product in both specimens and the increase is higher in specimen 75RH-DOL in areas with similar T1 and T2 values before treatment, this means that the humid environment favors the consolidation of the product giving rise to a higher density from the top to the bottom of the specimens. This increase in signal intensity values after the treatment could also be due to small differences in the experimental conditions. These differences could be avoided using an external reference to readjust the signal intensity values. The use of the signal of voxels entirely occupied by water as an internal reference has been reported [29]. In our case the pore sizes would not be wide enough to assume this assumption.

\subsubsection{Nuclear Magnetic Resonance (NMR): Relaxometry}

Relaxometry distribution curves of $\mathrm{T} 1$ and $\mathrm{T} 2$ relaxation times of both specimens before and after treatment are shown in Fig.9 and Fig.10. Before treatment, the T1 curve of specimen 33RH-DOL is slightly narrower compared to the T1 curve of specimen 75RH-DOL (Fig.9). This can be interpreted as greater microestructural homogeneity, due to the presence of pores of nearly the same dimension of those from specimen 33RH-DOL. However, after treatment T1 curve of specimen 33RH-DOL slightly changes, 
just a small shift of the peak towards higher relaxation times, indicating the presence of larger pores [27]. This is in agreement with ESEM results where it was observed that some pores became larger due to the dolomite attack by the consolidating product in a dry environment. The T1 relaxometry distribution curve of specimen 33RH-DOL shows that the longest relaxation times are not very different for the treated and untreated sample. This observation suggests that the treatment does not greatly change the surface relaxivity and guarantees that the variations of the $\mathrm{T} 1$ distribution can be described in terms of changes in the surface-to-volume ratios for the pore space accessible to water molecules [30]. However, after treatment, T1 curve of specimen 75RH-DOL shows significant differences, since it goes from a monomodal to a bimodal distribution, giving rise to a narrower curve and the appearance of a broad peak with a low signal but with shorter relaxation times (Fig.9). This behavior in 75RH-DOL where T1 decreases can be explained by more interconnected porosity and in smaller pores [27]. The slight narrowing of the larger curve can be explained by a higher homogeneity in some pores but the appearance of another broader small peak (bimodal distribution) showing wider distributions, reflects the presence of larger pores.

The peak of the T1 distribution curve of specimen 33RH-DOL after treatment is displaced towards longer $\mathrm{T} 1$ values although the tail of the curve is displaced towards slightly shorter T1 values. Capillarity test results have shown that connected porosity of this latter specimen was slightly reduced after treatment. However, the water absorption obtained under vacuum is very similar before and after treatment. The results from ESEM observations shown that pores between dolomite crystals are dissolved and fractured and these pores become larger after treatment. However, water absorption under vacuum in specimen 75RH-DOL significantly decreases after treatment and the decrease in capillarity coefficient $(C)$ gives rise to smaller pores and more connected porosity. A stone sample fully saturated with water shows longer T1 and T2 values than when it is not saturated [31,32]. A small pore surrounded by small but well connected pores will give a single peak in the relaxation time distribution [29]. Shorter times in the distribution of water and shift toward longer times could mean the formation of microfractures and the increase of local surface-to-volume ratios; the larger the ratio between the pore volume and its surface area, the longer the T1 value [31,32]. Therefore, if specimen $75 \mathrm{RH}-\mathrm{DOL}$, before treatment had cracks and big pores due to freezing-thawing cycles, the shift of $\mathrm{T} 1$ curve towards shorter times could mean also the disappearance of the pre-existing cracks. A T1 curve with a tail at short time means higher surface-to- 
volume ratio regions, and a wide peak extending to times greater than $1000 \mathrm{~ms}$ means lower surface-tovolume ratios [29]. The corresponding T2 distributions (Fig.10) are shifted towards shorter times and differently from T1 distributions (which are monomodal). The T2 distribution curve of specimen 75RHDOL after treatment has substantial amplitude below $1000 \mathrm{~ms}$, suggesting the possible presence of microporosity [30]. The areas under the T1 distribution curves (Fig.9) are roughly consistent with the percentages of water absorbed.

\section{Conclusions}

The non-destructive techniques (NDT) used in this research have shown to be fast, precise and reliable to determine the chemical, morphological, physical and hydric properties of dolostone and to evaluate the effectiveness of nanoparticles of calcium hydroxide as consolidating product for carbonate stones. The high $\mathrm{RH}$ conditions (75\% RH) favor the consolidation process of dolostone as observed under ESEM and MRI, and quantified through capillarity, water absorption under vacuum, ultrasounds velocity, NMR (MRI and relaxometry) and OSR analyses. Although the consolidation process has improved the physical and hydric properties of the stone specimens on both dry $(33 \% \mathrm{RH})$ and humid environment $(75 \% \mathrm{RH})$ : 1-In low humidity conditions $(33 \% \mathrm{RH})$ the XRD analyses of the consolidating product, mainly show the presence of portlandite $\left(\mathrm{Ca}(\mathrm{OH})_{2}\right)$; as observed and analyzed under ESEM-EDS it mainly covers the crystal surfaces, favors the calcite $\left(\mathrm{CaCO}_{3}\right)$ re-crystallization but produces the dissolution and fracture of dolomite $\left(\mathrm{CaMg}\left(\mathrm{CO}_{3}\right)_{2}\right)$ crystals. Therefore this product could be good to consolidate limestone (with high percentage of calcium carbonate) in these conditions. For dolostone or magnesian limestone, would be better to use this product in high humidity conditions $(75 \% \mathrm{RH})$, since it fills the pores and intercrystalline dolomite grain contacts, it does not favor the calcite re-crystallization but does not attack dolomite crystals. XRD analyses reveal the fast transformation of portlandite into vaterite $\left(\mathrm{CaCO}_{3}\right)$, monohydrocalcite $(\mathrm{CaCO} 3 \cdot \mathrm{H} 2 \mathrm{O})$ and calcite at $75 \% \mathrm{RH}$.

2-TEM results indicate that in high $\mathrm{RH}$ conditions $(75 \% \mathrm{RH})$ there is a faster crystal growth rate with larger crystal sizes from nanometric to micrometric scale compared to lower RH conditions (33\% RH), which particle sizes only reach the nanometric scale after 20 days of consolidation.

3-The consolidating product does not significantly affect the stone colour parameters after treatment. 
4-The average surface roughness (3D topographic maps) obtained by OSR of both specimens is slightly modified, except on the top surface of the specimen exposed to low HR (33\%RH) where $R a$ decreases due to the deposition layer of calcium hydroxide nanoparticles on the surface of the stone.

5- The open porosity and saturation values decrease after treatment and the ultrasounds velocity significantly increases along the three spatial directions, in the specimen with higher porosity exposed to high humidity environment, due to a better and more homogeneous distribution of the consolidating product. The capillarity coefficient (rate of water transport) decreases due to a smaller connected porosity. In the specimen with lesser and smaller porosity exposed to low humidity environment, the capillarity coefficient, the open porosity and water absorption values slightly decrease and the ultrasounds velocity slightly increase only in one spatial direction.

6-NMR results allowed comparing same pore sizes common in both specimens before and after the treatment. The center of both specimens is the area with higher decrease in $\mathrm{T} 1$ and $\mathrm{T} 2$ relaxation times related with a decrease in the pore sizes and the generation of smaller pore sizes. The shift of the relaxometry distribution curve (T1) towards shorter times caused by the consolidating product indicates the filling of big pores and the disappearance of the pre-existing cracks.

7-The abundance of larger pore sizes (pore diameter $100 \mu \mathrm{m}$ ) together with the high humidity environment has favored the consolidation of the dolostone with calcium hydroxide nanoparticles of 30$60 \mathrm{~nm}$ size penetrating more homogeneously through the pores of the stone in a really fast carbonation process.

\section{Acknowledgements}

This study was funded by the Government of the Community of Madrid under the project "Durability and conservation of traditional natural materials in heritage architecture" (MATERNAS CM 0505/MAT/0094) and the Spanish Ministry of Science and Innovation as part of the Consolider-Ingenio 2010 programme (CSD2007-0058). We thank C.T.S. S.R.L for supplying the consolidating product Nanorestore®. The authors thank the Marie Curie Fellowships for supporting to L.Pinho and the JAE-Doc CSIC contract for supporting P.López-Arce to develop this work. The authors are grateful to Laura Tormo and Marta Furió of the Natural Science Museum (CSIC) for providing the ESEM-EDS photographs and analyses. Special thanks go to Inmaculada Ruiz and Iván Serrano, IGE (Institute of Economic Geology) petrophysics laboratory technicians, to Emilio Matesanz from XRD CAI (UCM) for his help 
with the XRD analyses and Juan Luis Baldonedo from the Microscopy and Citommetry Centre (UCM) for his support with the TEM analyses.

\section{REFERENCES}

1. A. Hernanz, I. Bratu, O.F. Marutoiu, C. Marutoiu, J.M. Gavira-Vallejo and H.G.M. Edwards, Micro-Raman spectroscopic investigation of external wall paintings from St. Dumitru's Church, Suceava, Romania, Analytical and Bioanalytical Chemistry 392 (2008), pp. 263-268.

2. P. López-Arce, J. García Guinea, M. Gracia and J. Obis, Bricks in historical buildings of Toledo City: characterisation and restoration, Materials Characterization, 50 (2003), pp-59-68.

3. P. López-Arce, D. Benavente and J. García-Guinea, Durability Improvement of Ancient Bricks by Cementation of Porous Media, Journal of the American Ceramic Society 88 (9) (2005), pp. 2564-2572.

4. V. Daniele, G. Taglieri and R. Quaresima, The nanolimes in Cultural Heritage conservation: Characterisation and analysis of the carbonatation process, Journal of Cultural Heritage 9 (3) (2008), pp. 294-301.

5. E. Hansen, E. Doehne, J. Fidler, J. Larson, B. Martin, M. Matteini, C. Rodriguez-Navarro, E. Sebastián Pardo, C. Price, A. de Tagle, J.M. Teutonico and N. Weiss. A review of selected inorganic consolidants and protective treatments for porous calcareous materials, Reviews in Conservation 4 (2003), pp. 13-25.

6. R. Giorgi, L. Dei and P. Baglioni, A new method for consolidating wall paintings based on dispersions of lime in alcohol, Studies in Conservation 45 (2000), pp. 154-161.

7. M. Ambrosi, L. Dei, R. Giorgi, C. Neto and P. Baglioni, Colloidal particles of $\mathrm{Ca}(\mathrm{OH})_{2}$ : properties and applications to restoration of frescoes, Langmuir 17 (2001), pp. 4251-4255.

8. B. Salvadori and L. Dei, Synthesis of $\mathrm{Ca}(\mathrm{OH}) 2$ nanoparticles from diols, Langmuir 17 (2001), pp. 2371-2374.

9. L. Dei and B. Salvadori, Nanotechnology in cultural heritage conservation: nanometric slaked lime saves architectonic and artistic surfaces from decay, Journal of Cultural Heritage 7 (2) (2006), pp. 110-115.

10. A.E. Charola, G.E. Wheeler and G.G. Freund, The influence of relative humidity in the polymerization of methyl trimethoxysilane. In: N.S. Brommelle, E.M. Pye, P. Smith, G. Thomson (Eds.). Preprints of the contributions to the IIC Paris Congress Adhesives and consolidants, London, IIC; 1984, p. 177-183.

11. R.M. Dheilly, J. Tudo, Y. Sebaibi and M. Quéneudec, Influence of storage conditions on the carbonation of powdered $\mathrm{Ca}(\mathrm{OH}) 2$, Construction and Building Materials 16 (2002), pp. 155-161.

12. S. Sanchez-Moral, J. Garcia-Guinea, L. Luque, R. Gonzalez-Martin and P. Lopez-Arce, Carbonation kinetics in roman-like lime mortars, Materiales de Construccion 54 (275) (2004), pp. 23-36.

13. A. El-Turki, R.J. Ball and G.C. Allen. The influence of relative humidity on structural and chemical changes during carbonation of hydraulic lime, Cement and Concrete Research 37 (2007), pp. 1233-1240. 
14. M. Drdácký and Z. Slížková. Calcium hydroxide based consolidation of lime mortars and stone. In: J. Delgado Rodrigues, J.M. Mimoso (Eds.). Proceedings of the International Symposium Stone consolidation in cultural heritage, Laboratorio Nacional de engenharia civil, Lisbon; 2008, p. 299-308.

15. G. Ziegenbalg, Colloidal calcium hydroxide - a new material for consolidation and conservation of carbonatic stones. In: J,W, Lukaszewick, P, Niemcewicz (Eds.). Proceedings of the 11th International Congress on Deterioration and Conservation of Stone, Poland; 2008, p. 1109-1115.

16. P. Tiano, E. Cantisani, I. Sutherland and J.M. Paget. Biomediated reinforcement of weathered calcareous stones. Journal of Cultural Heritage 7 (2006), pp. 49-55.

17. G.C. Borgia, M. Camaiti, F. Cerri, P. Fantazzini and F. Piacenti, Study of water penetration inside rock materials by nuclear magnetic resonance tomography: hydrophobic treatment effects, Journal of Cultural Heritage 1 (2000), pp. 127-132.

18. G.C. Borgia, M. Camaiti, F. Cerri, P. Fantazzini and F. Piacenti. Hydrophobic treatments for stone conservation: influence of the application method on penetration, distribution, and efficiency, Studies in Conservation 48 (2003), pp. 217-226.

19. R. Fort, B. Fernández-Revuelta, M.J. Varas, M. Alvarez de Buergo and M. Taborda-Duarte, Influence of anisotropy on the durability of Madrid-region Creaceous dolostone exposed to salt crystallization processes. Materiales de Construccion 58(289-290) (2008), pp. 161-178.

20. International Organization for Standardization DIN EN ISO: 4287. Surface roughness—terminology: Part 1. Surface and its parameters.

21. AENOR Spanish Association for Standardisation and Certification UNE-EN 14579:2005. Natural stone test methods. Determination of sound speed propagation.

22. AENOR Spanish Association for Standardisation and Certification UNE-EN 1936:1999. Natural stone test methods. Determination of real density and apparent density, and of total and open porosity.

23. G.C. Borgia, R.J.S. Brown and P. Fantazzini, Uniform-Penalty inversion of multiexponential decay data II: data spacing, T2 data, systematic data errors, and diagnostics. Journal of Magnetic Resonance 147 (2000), pp. 273-285.

24. S. Kamhi, On the structure of vaterite $\mathrm{CaCO}_{3}$, Acta Crystallographica 16 (1963), pp. 770-772.

25 J. Delgado Rodrigues and A. Grossi, Indicators and ratings for the compatibility assessment of conservation actions, Journal of Cultural Heritage 8 (2007), pp. 32-43.

26. P. Lopez-Arce, J. Garcia-Guinea, D. Benavente, L. Tormo and E. Doehne, Deterioration of dolostone by magnesium sulphate salt: an example of incompatible building materials at Bonaval Monastery, Spain. Construction and Building Materials 23 (2) (2009), pp. 846-855. 
27. R. Viola, A. Tucci, G. Timellini and P. Fantazzini, NMR techniques: A non-destructive analysis to follow microstructural changes induced in ceramics, Journal of European Ceramic Society 26 (2006), pp. 3343-3349.

28. P. Fantazzini, A. Salem, G. Timellini, A. Tucci and R.Viola, Microstructure changes in fired ceramics quantified by magnetic resonance relaxation and imaging, Journal of Applied Physics 94 (2003), pp. 5337-5342.

29. G.C. Borgia, V. Bortolotti and P.Fantazzini, Changes of the local pore space structure quantified in heterogeneous porous media by $1 \mathrm{H}$ magnetic resonance relaxation tomography, Journal of Applied Physics 90 (3) (2001), pp. 1155-1163.

30. M. Camaiti, C. Casieri, F. De Luca, P. Fantazzini and C.Terenzi, The use of portable single-sided relaxometry and laboratory imaging NMR devices in Stone conservation, Studies in Conservation 52 (2007), pp. 37-49.

31. M. Alesiani, S. Capuani and B. Maraviglia, NMR study on the early stages of hydration of a porous carbonate stone, Magnetic Resonance Imaging 21 (4) (2003), pp. 333-335.

32. M. Alesiani, S. Capuani and B. Maraviglia, NMR applications to low porosity carbonate stones, Magnetic Resonance Imaging 21 (7) (2003), pp. 799-804. 


\section{FIGURE CAPTIONS}

Fig. 1 - X-ray Diffraction (XRD) of the calcium hydroxide nanoparticles product at different consolidation days in humid $(75 \% \mathrm{RH})$ and dry environment $(33 \% \mathrm{RH})$ showing the changes in the mineral phases during the carbonation process. a) 75\% RH after 5 days; b) 33\% RH after 5 days; c) 75\% RH after 12 days; d) 33\% RH after 12 days; e) 75\% RH after 20 days and f) $33 \%$ RH after 20 days.

Fig. 2 - Transmission Electron Microscopy (TEM) images in bright field mode of nanoparticles. a) calcium hydroxide nanoparticles "as deposited"; b) selected area electron diffraction pattern ( $s a e d p$ ) of portlandite phase after 5 days in $75 \%$ relative humidity and c) saedp of vaterite phase after 5 days in $75 \%$ relative humidity.

Fig. 3 - Environmental Scanning Electron Microscopy (ESEM) images of the calcium hydroxide nanoparticles product at different consolidation days in humid $(75 \% \mathrm{RH})$ and dry environment (33\% $\mathrm{RH})$ showing the morphology of the crystals during the carbonation process. a) 75\% RH after 5 days; b) 33\% RH after 5 days; c) 75\% RH after 12 days; d) 33\% RH after 12 days; e) 75\% RH after 20 days and f) 33\% RH after 20 days.

Fig. 4 - ESEM images of stone specimens before and after consolidation at 75\%RH and the optical linescan profiles obtained after processing of images with Digital Micrograph software ${ }^{\mathrm{TM}}$. a) pore in specimen 75RH-Dol before consolidation; b) same pore in specimen 75RH-Dol after consolidation 20 days later; c) contacts between dolomite crystals (Dol); d) same contacts between dolomite crystals after consolidation 20 days later.

Fig. 5 - ESEM images of stone specimens before and after consolidation at 33\% RH and the optical linescan profiles obtained after processing of images with Digital Micrograph software ${ }^{\mathrm{TM}}$. a) pore in specimen 33RH-Dol before consolidation; b) same pore in specimen 33RH-Dol after consolidation; c) calcite crystal (Cc) in specimen 33RH-Dol before consolidation 20 days later; d) same calcite crystal (Cc) specimen 33RH-Dol after consolidation 20 days later.

Fig.6 - Surface roughness 3D height map obtained under Optical Surface Roughness (OSR) on the top surface of specimen 33RH-DOL in the area $25 \mathrm{~mm}^{2}$, a) before consolidation $(\mathrm{Ra}=14.68 \pm 2.29 \mu \mathrm{m}$; $\mathrm{Rq}=8.98 \pm 2.04 \mu \mathrm{m}$; $\mathrm{Rz}=$ 
$29.44 \pm 5.80 \mu \mathrm{m}$ ); two surface roughness profiles were measured on this area (see Table 2 and Fig.7b); b) after consolidation $(\mathrm{Ra}=6.93 \pm 1.76 \mu \mathrm{m} ; \mathrm{Rq}=9.05 \pm 2.33 \mu \mathrm{m} ; \mathrm{Rz}=29.66 \pm 6.59 \mu \mathrm{m}) ; \mathrm{c}) 2 \mathrm{D}$ height map before consolidation of same area shown in Fig.6a; d) 2D height map after consolidation of same area shown in Fig.6b. White, pink and red colours show the highest heights and blue, purple and black colours show the deepest depths.

Fig. 7 - Surface roughness profiles of the surface of dolostone specimens obtained under Optical Surface Roughness (OSR), before and after consolidation in: a) humid $(75 \% \mathrm{RH})$ and b) dry environment $(33 \% \mathrm{RH})$. The surface roughness optical values corresponding to these profiles are given in Table 2 and the profiles 1 and 2 of specimen 33RH-Dol are also drawn in Fig.6a.

Fig. 8 - Capillarity curves obtained after water absorption by capillarity test of the stone specimens before (75RHDOL and 33RH-DOL) and after consolidation (75\%RH-DOL-Nano and 33RHDOL-Nano) with calcium hydroxide nanoparticles.

Fig. 9 - Relaxation time T1 distribution curves of the stone specimens before (75RH-DOL and 33RH-DOL) and after consolidation (75\%RH-DOL-Nano and 33RHDOL-Nano) obtained by Nuclear Magnetic Resonance (Relaxometry).

Fig. 10 - Relaxation time T2 distribution curves of the stone specimens before (75RH-DOL and 33RH-DOL) and after (75\%RH-DOL-Nano and 33RHDOL-Nano) consolidation obtained by Nuclear Magnetic Resonance (Relaxometry). 


\section{TABLE CAPTIONS}

Table 1 - Colour variation promoted on the dolostone specimens after treatment with Nanorestore ${ }^{\circledR} . \Delta \mathrm{L}^{*}$ is the variation in luminosity, $\Delta \mathrm{a}^{*}$ is the variation in the red-green parameter, $\Delta \mathrm{b}^{*}$ is the variation in the blue-yellow parameter, $\Delta \mathrm{YI}$ is the variation in the yellow index (measured according to ASTM 313-76) and $\Delta \mathrm{E}^{*}$ is the total colour difference.

Table 2 - Variation in roughness parameters measured on the top and the bottom of the dolostone specimens, before and after consolidation with lime nanoparticles at $75 \%$ and $33 \%$ relative humidity $(75 \mathrm{RH}-\mathrm{DOL}$ and $33 \mathrm{RH}-\mathrm{DOL}$, respectively).

Table 3 - Ultrasounds velocity values for dolostone specimens, before and after consolidation with lime nanoparticles at $75 \%$ (75RH-DOL) and 33\% relative humidity (33RH-DOL).

Table 4 - Water absorption by capillarity results of dolostone specimens, before and after consolidation with lime nanoparticles at $75 \%$ (75RH-DOL) and 33\% (33RH-DOL) relative humidity.

Table 5 - Water absorption under vacuum results of dolostone specimens, before and after consolidation with lime nanoparticles at $75 \%$ (75RH-DOL) and 33\% relative humidity (33RH-DOL).

Table 6 - Results of Nuclear Magnetic Resonance Imaging (MRI) obtained in three slices along Z axe with a thickness of $0.5 \mathrm{~cm}$ in three areas of $2.2 \mathrm{~cm}^{2}$ of specimen 75RH-DOL. T1 is longitudinal relaxation time, T2 is transversal relaxation time and PD is proton density.

Table 7 - Results of Nuclear Magnetic Resonance Imaging (MRI) obtained in three slices along Z axe with a thickness of $0.5 \mathrm{~cm}$ in three areas of $2.2 \mathrm{~cm}^{2}$ of specimen 33RH-DOL. T1 is longitudinal relaxation time, T2 is transversal relaxation time and $\mathrm{PD}$ is proton density. 


\title{
Influence of porosity and relative humidity on consolidation of dolostone with calcium hydroxide nanoparticles:
}

\section{Effectiveness assessment with non destructive techniques}

\author{
P.López-Arce ${ }^{\mathrm{a}, *}$, LS.Gomez-Villalba ${ }^{\mathrm{a}}$, L. Pinho ${ }^{\mathrm{b}}$, ME. Fernández-Valle ${ }^{\mathrm{c}}$, M. Álvarez de Buergo ${ }^{\mathrm{a}}$ \\ and R. Fort ${ }^{\mathrm{a}}$ \\ ${ }^{\mathrm{a}}$ Group of Applied Petrology to Heritage Conservation, Institute of Economic Geology (CSIC-UCM), \\ Madrid 28040, Spain, plopezar@geo.ucm.es \\ ${ }^{\mathrm{b}}$ Center of Construction Studies, Engineering Faculty, Oporto University, \\ Oporto 4200-465, Portugal
}

${ }^{c}$ Research Assistance Center, Nuclear Magnetic Resonance (Pluridisciplinar Institute), Complutense University of Madrid (UCM), Madrid 28040, Spain

\begin{abstract}
Slaked lime $\left(\mathrm{Ca}(\mathrm{OH})_{2}\right)$ nanoparticles were crystallized at $33 \%$ and $75 \%$ relative humidity (RH) to consolidate dolostone samples used in historical buildings. Non destructive techniques (NDT) were applied to determine the chemical, morphological, physical and hydric properties of the stone samples, before and after 20 days treatment. Morphological and mineralogical characterisation of the nanoparticles was performed. $75 \% \mathrm{RH}$ favours the consolidation process studied under Environmental Scanning Electron Microscopy (ESEM-EDS), spectrophotometry, capillarity, water absorption under vacuum, ultrasounds velocity, Nuclear Magnetic Resonance (imaging and relaxometry) and Optical Surface Roughness analyses. At $75 \%$ RH the nanoparticle fill the pores and inter-crystalline dolomite grain contacts but does not favour calcite re-crystallization as it occurs at 33\%RH. The ESEM, XRD and TEM analyses under $75 \% \mathrm{RH}$ reveal the fast transformation of portlandite $\left(\mathrm{Ca}(\mathrm{OH})_{2}\right)$ into vaterite $\left(\mathrm{CaCO}_{3}\right)$, monohydrocalcite $(\mathrm{CaCO} 3)$ and calcite $\left(\mathrm{CaCO}_{3}\right)$, and eventually the physical and hydric properties of the stones significantly improve. New insights are provided for the assessment of consolidation effectiveness of porous carbonate stones with calcium hydroxide nanoparticles under optimum RH conditions combining several NDT.
\end{abstract}


High-resolution Figure(s)

Click here to download high resolution image
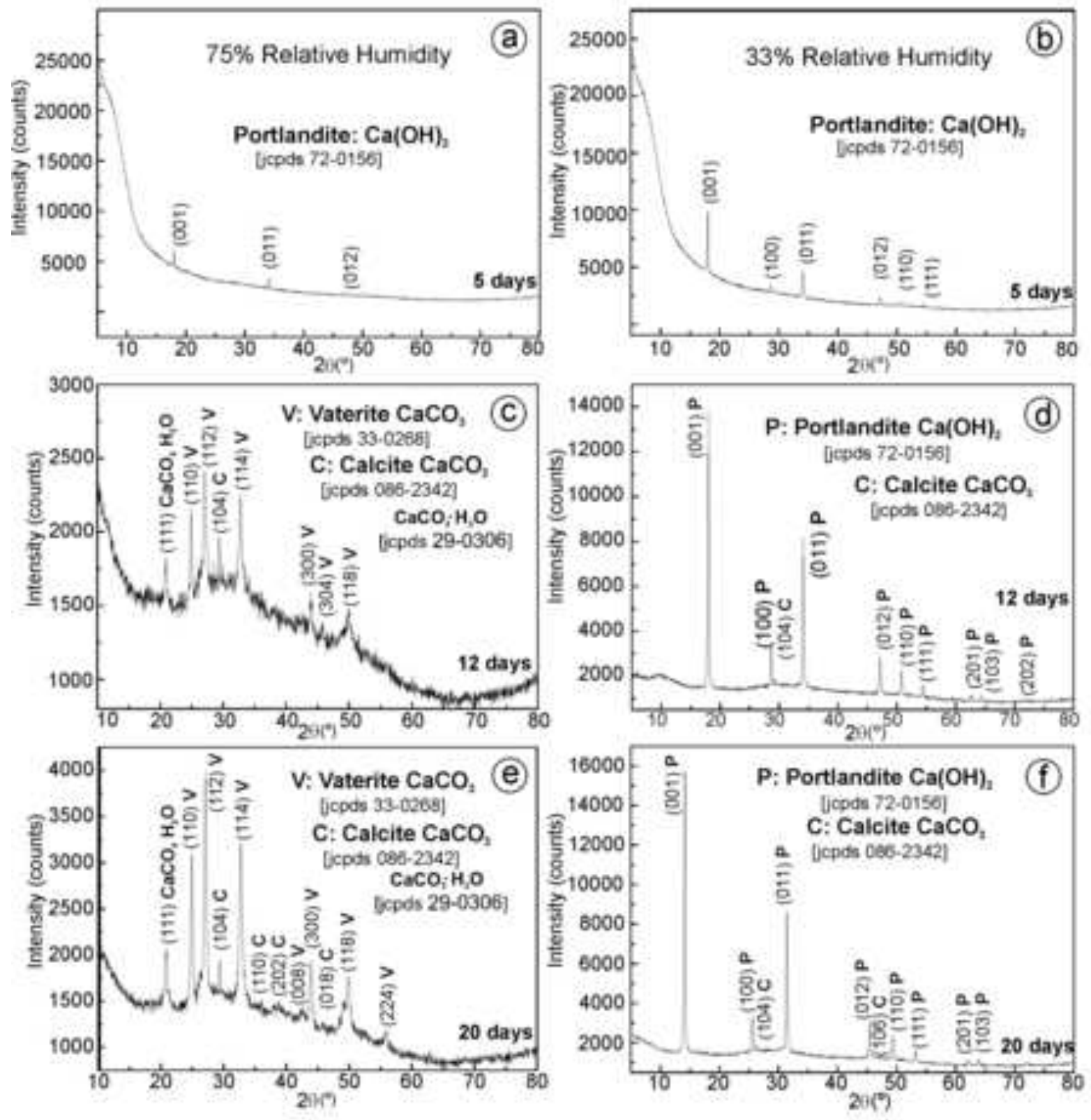

Figure 1

Lopez-Arce et al. 
High-resolution Figure(s)
Click here to download high resolution image
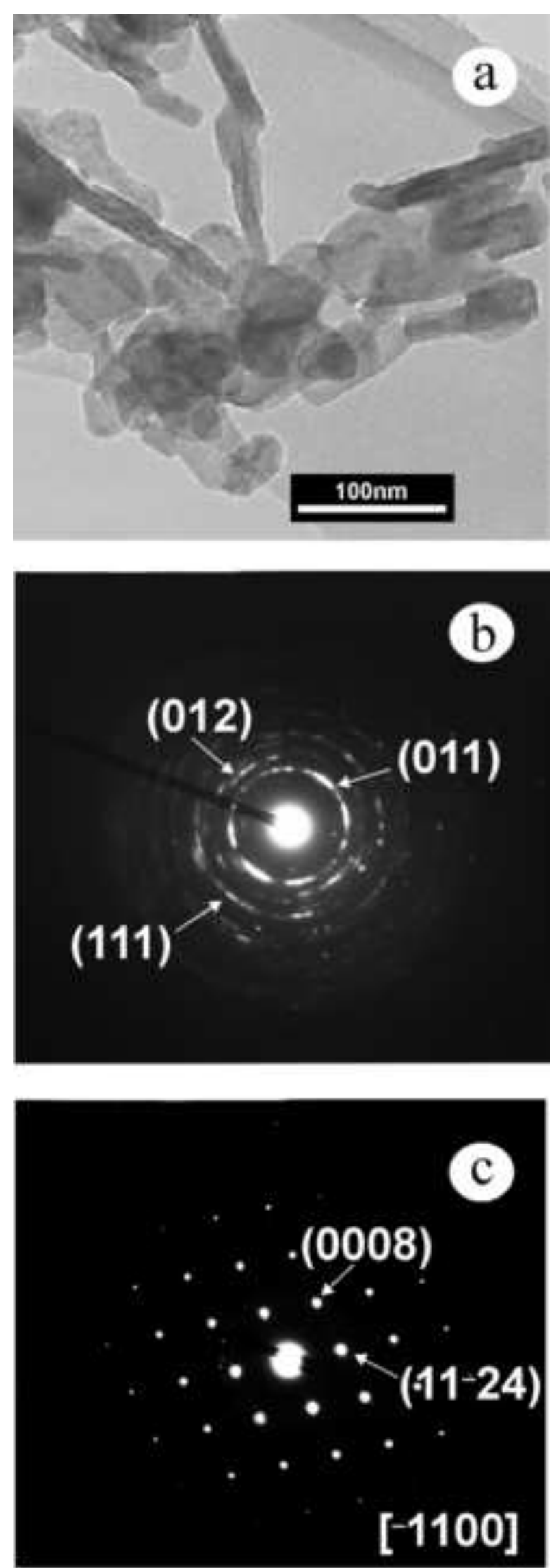

Figure 2 López-Arce et al. 
High-resolution Figure(s)

Click here to download high resolution image
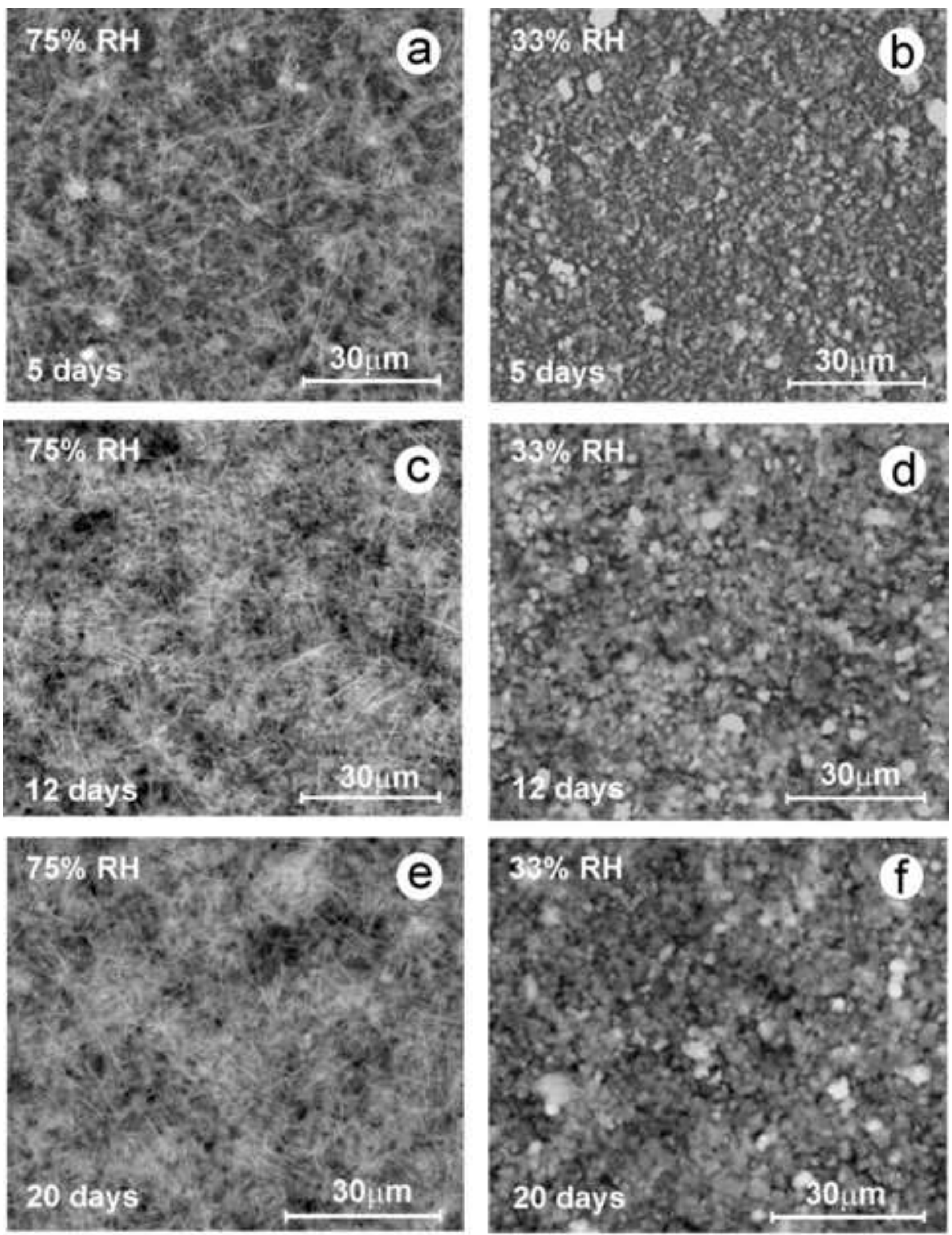

\section{Figure 3 \\ Lopez-Arce et al.}




\section{Click here to download high resolution image}
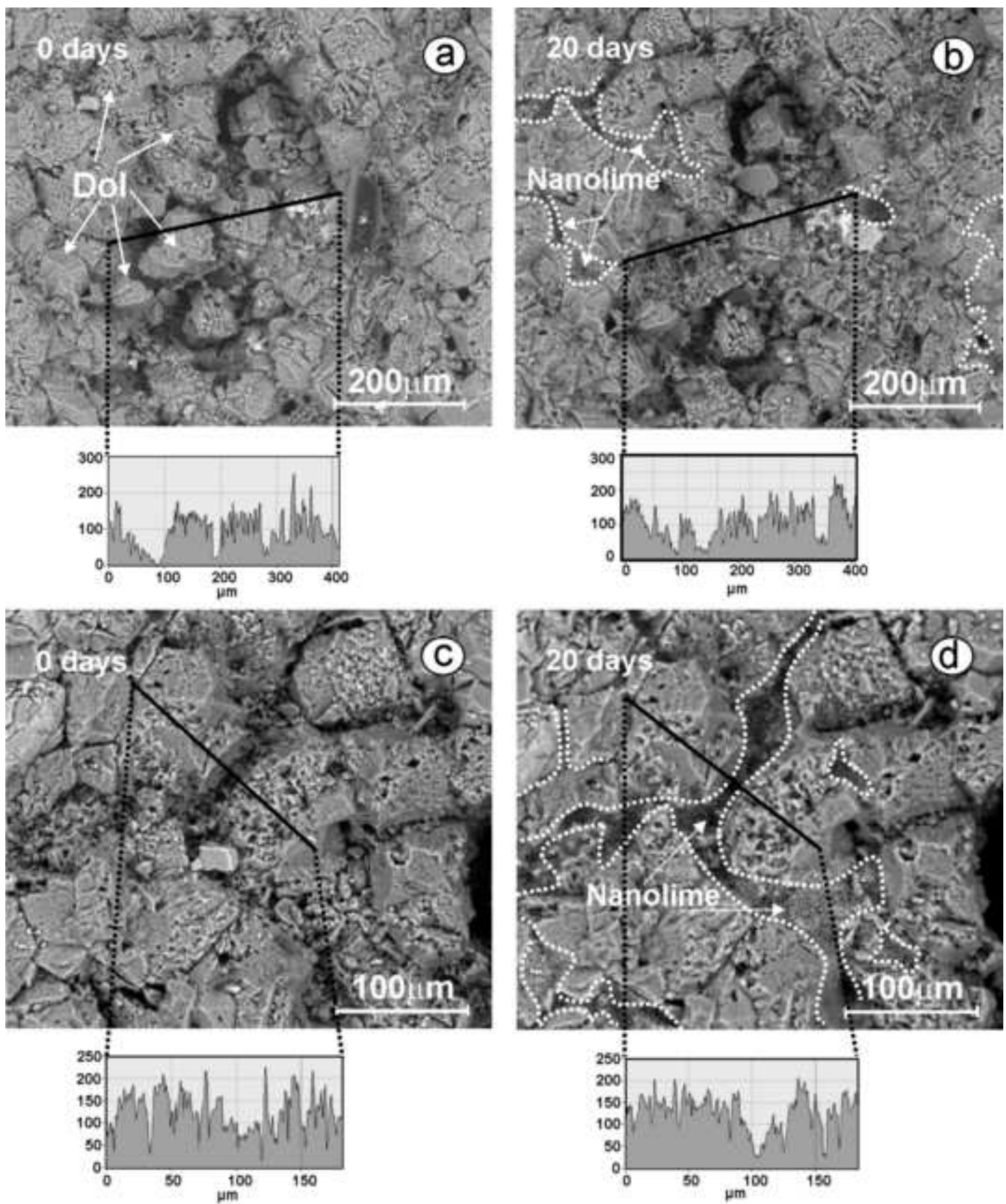

\section{López-Arce et al., \\ Figure 4}


High-resolution Figure(s)

Click here to download high resolution image
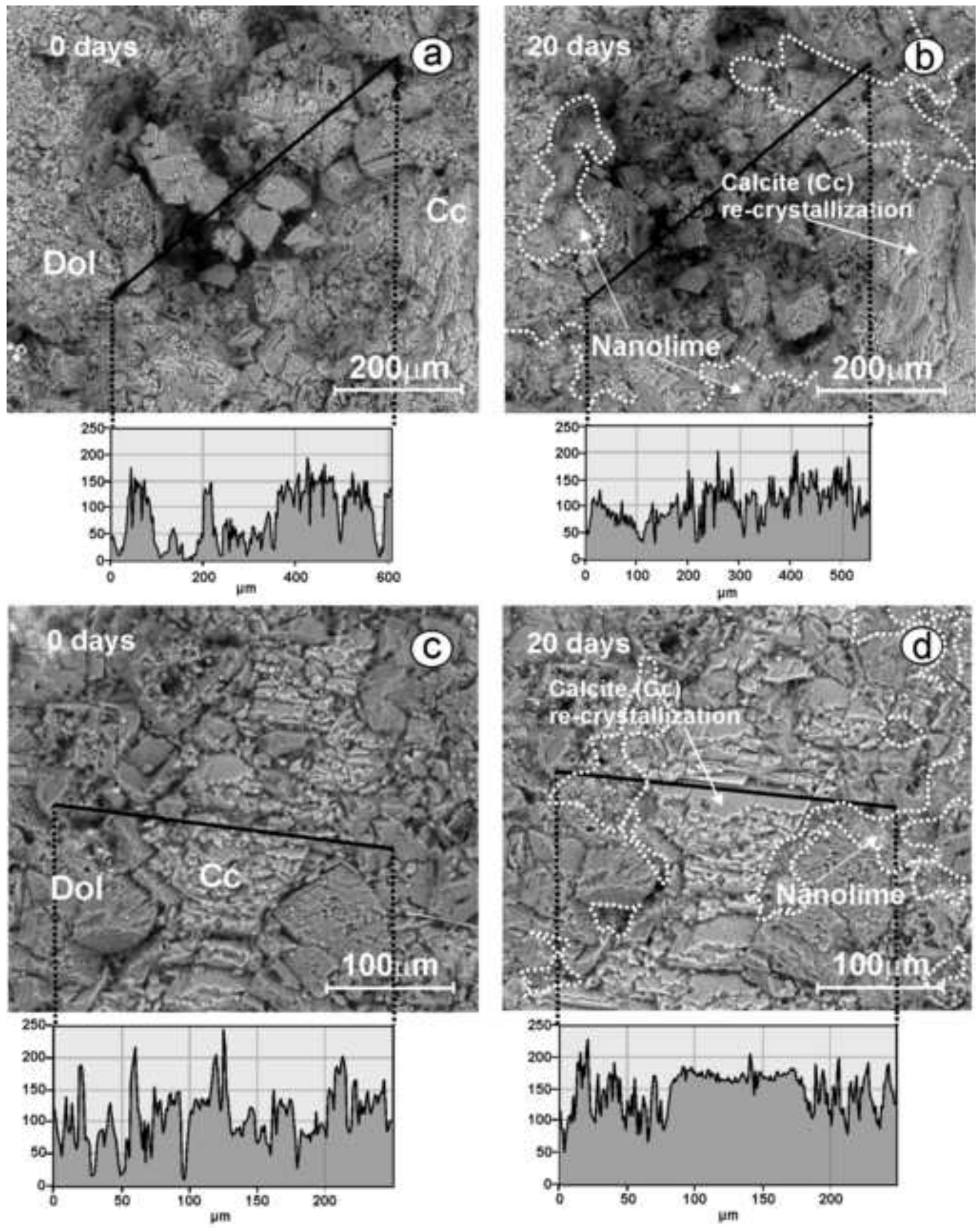

López-Arce et al.,

Figure 5 

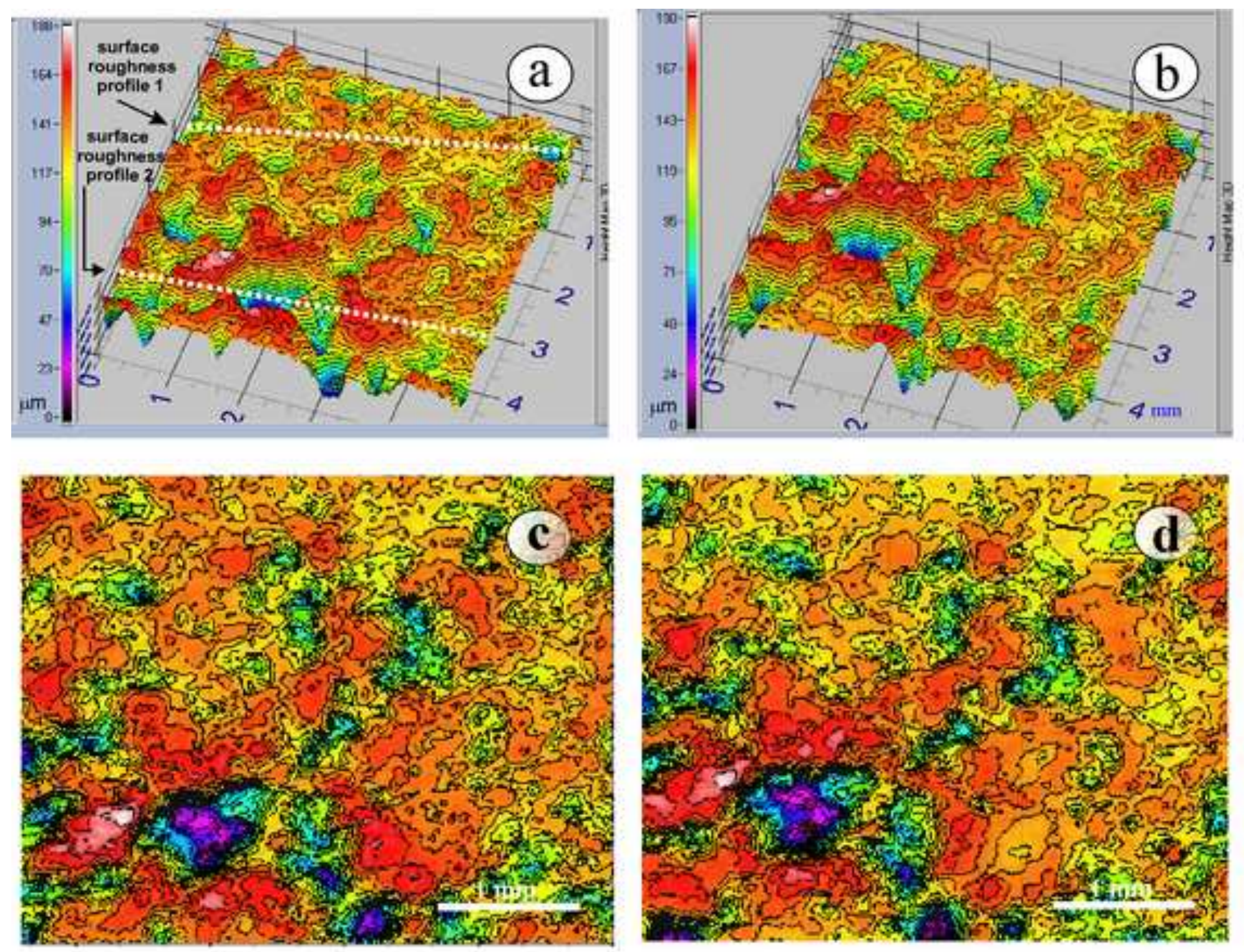

\section{Figure 6} López-Arce et al. 

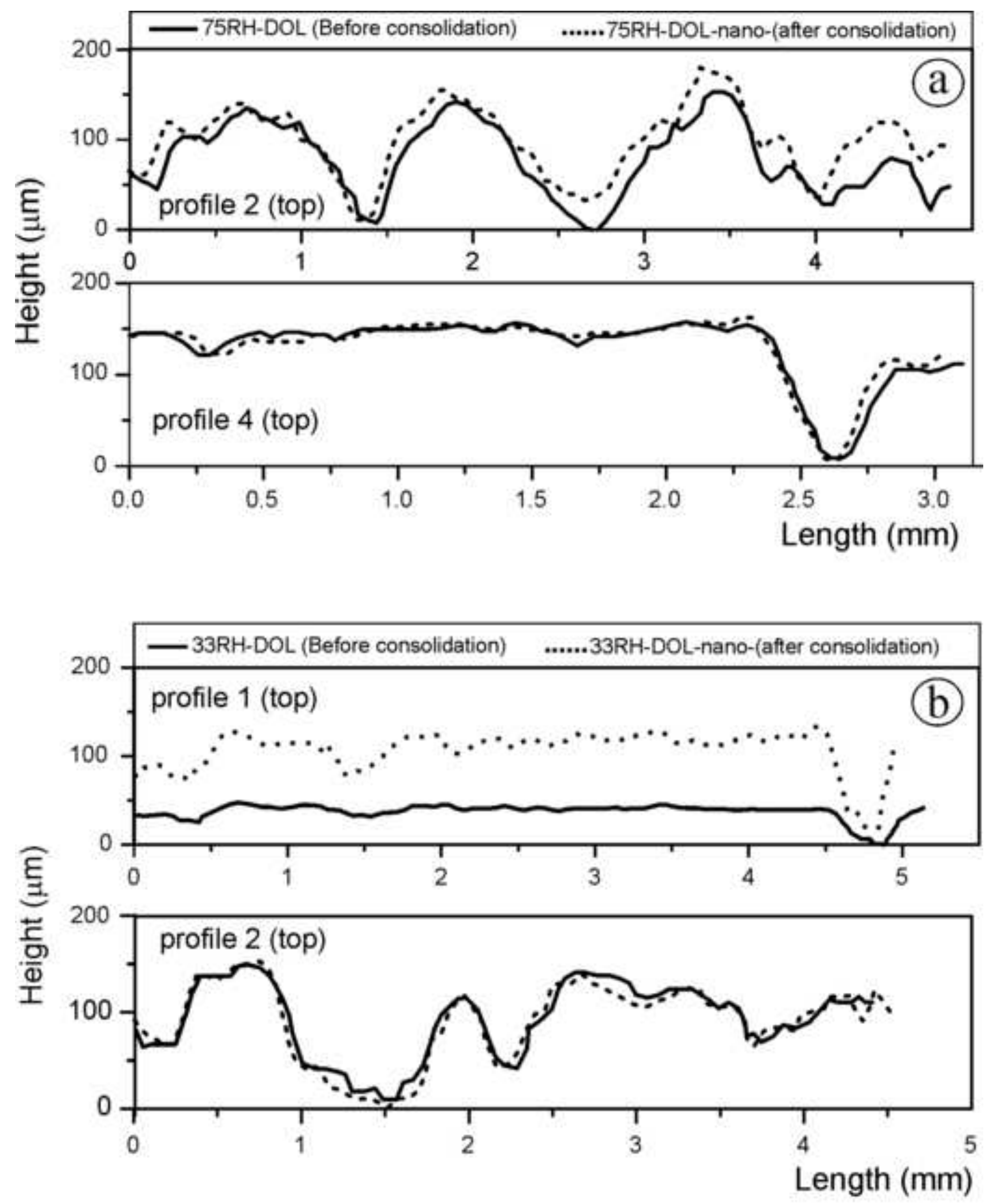

Figure 7

López-Arce et al., 
Click here to download high resolution image

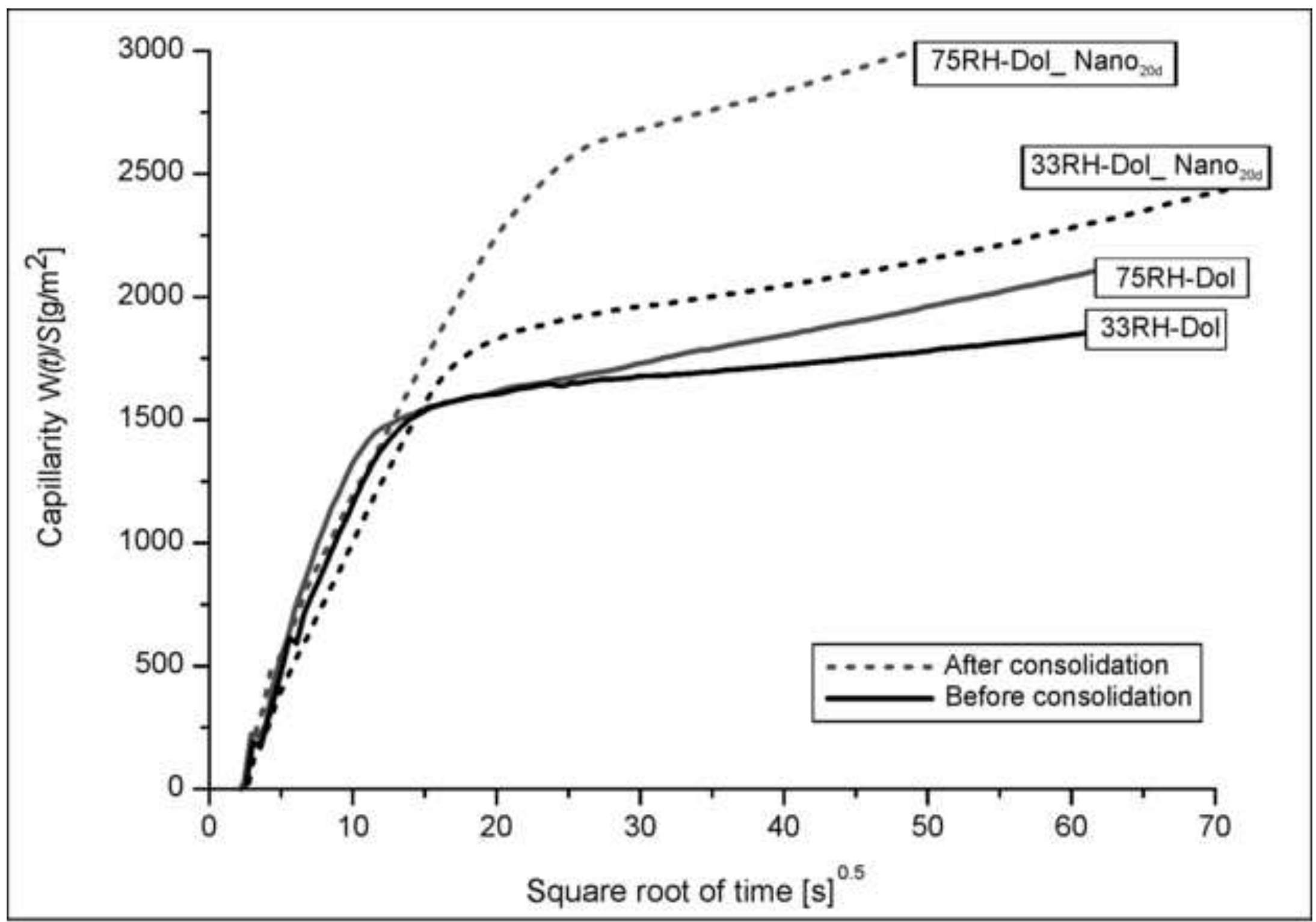

Figure 8

López-Arce et al., 
High-resolution Figure(s)

Click here to download high resolution image

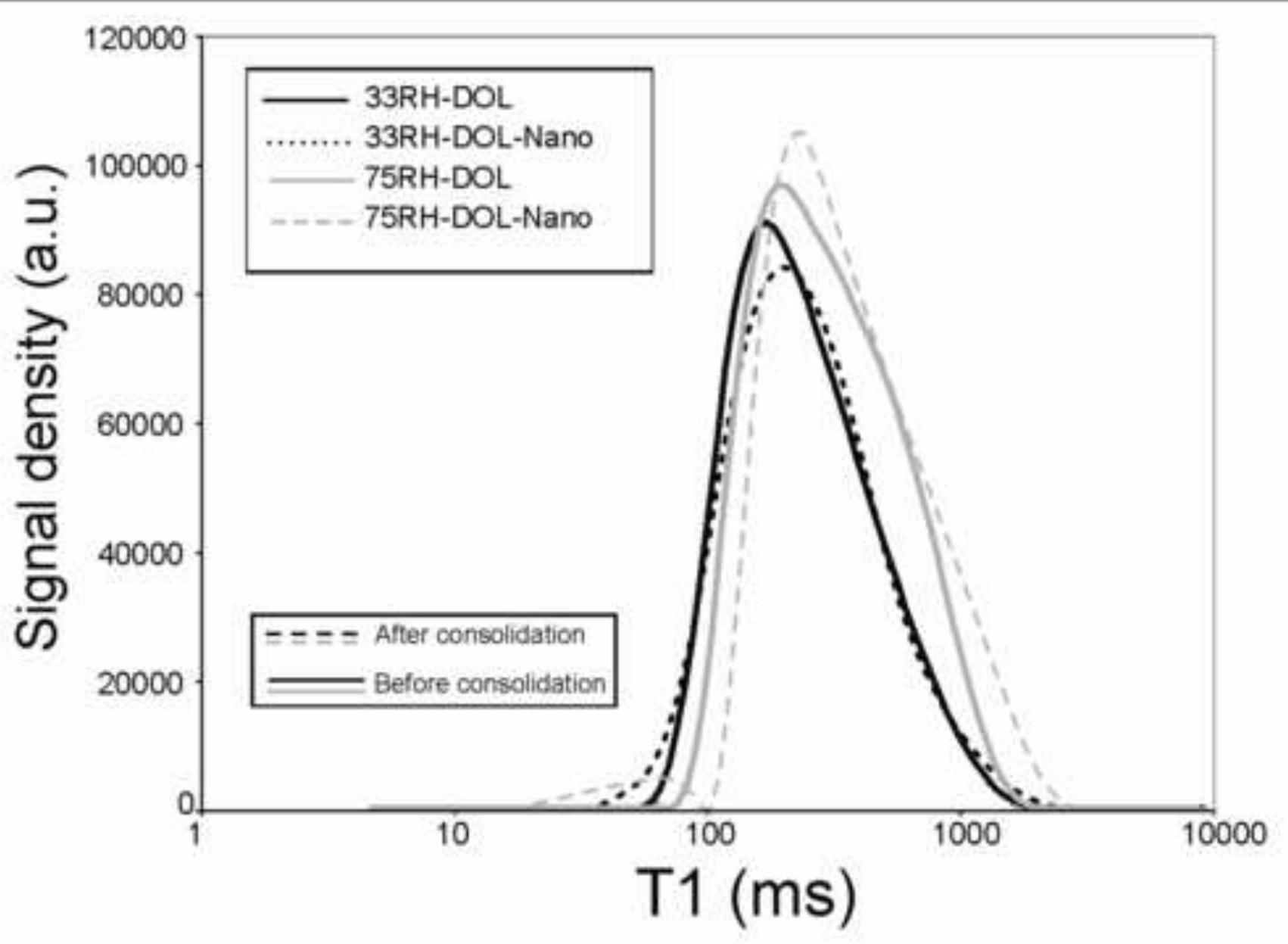

Figure 9

López-Arce et al 
Click here to download high resolution image

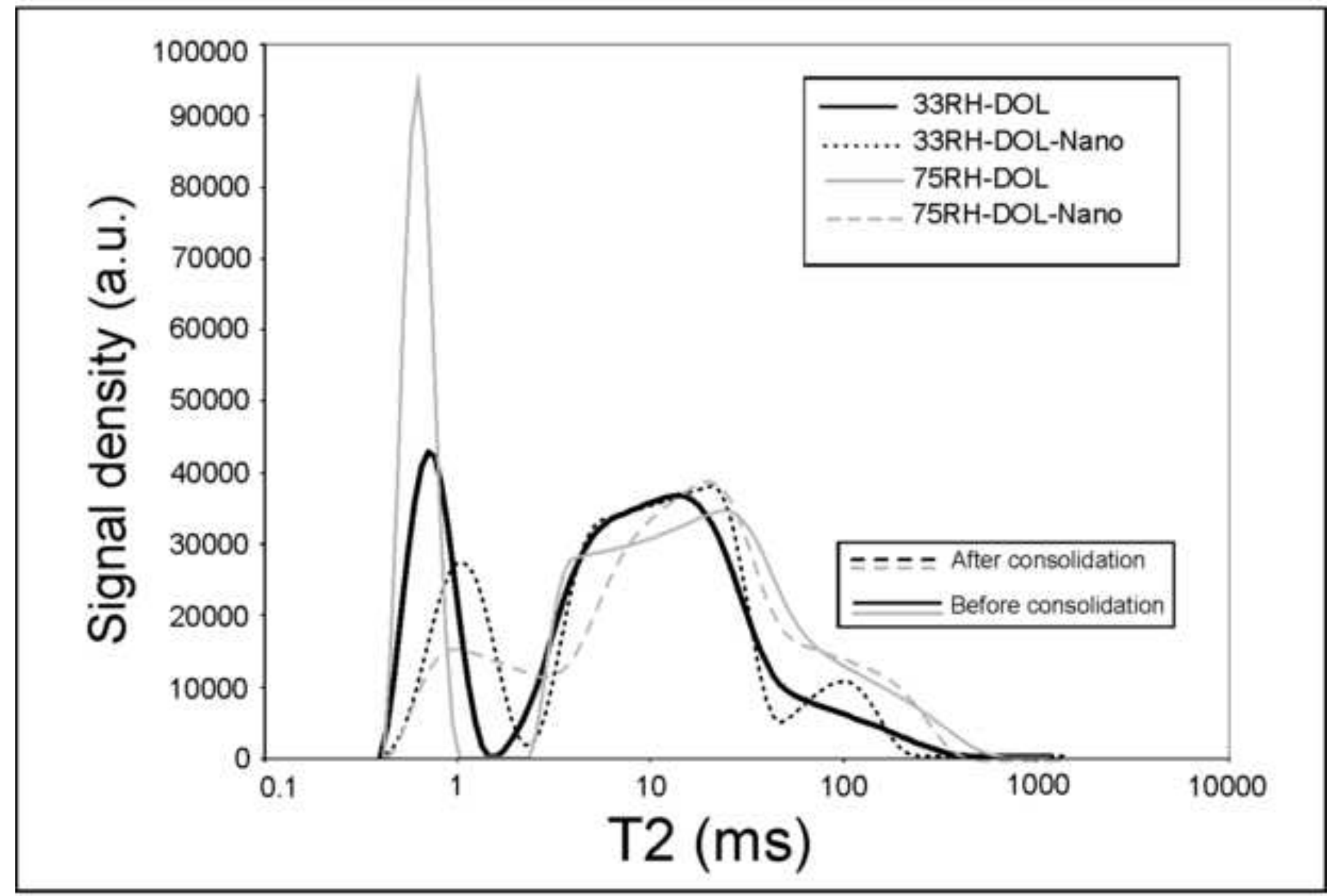

\section{Figure 10 López-Arce et al}


Table(s)

Table 1

\begin{tabular}{lccccc}
\hline Specimen & $\Delta \mathrm{L}^{*}$ & $\Delta \mathrm{a}^{*}$ & $\Delta \mathrm{b}^{*}$ & $\Delta \mathrm{E}^{*}$ & $\Delta \mathrm{YI}$ \\
\hline 75RH-DOL & 1.82 & 0.65 & -1.77 & 2.61 & -4.57 \\
33RH-DOL & 1.33 & -1.53 & -3.99 & 4.74 & -9.36 \\
\hline
\end{tabular}




\section{Table 2}

\begin{tabular}{|c|c|c|c|c|c|c|c|c|c|}
\hline \multirow{2}{*}{$\begin{array}{l}\text { Surface } \\
\text { Rougness }\end{array}$} & \multicolumn{2}{|c|}{$\mathrm{Ra}(\mu \mathrm{m})$} & \multirow{2}{*}{$\begin{array}{l}\nabla / \Delta \\
(\%)\end{array}$} & \multicolumn{2}{|c|}{$\mathrm{Rq}(\mu \mathrm{m})$} & \multirow{3}{*}{$\begin{array}{l}\nabla / \Delta \\
(\%)\end{array}$} & \multicolumn{2}{|c|}{$\mathrm{Rz}(\mu \mathrm{m})$} & \multirow{3}{*}{$\begin{array}{l}\nabla / \Delta \\
(\%)\end{array}$} \\
\hline & Before & After & & Before & After & & Before & After & \\
\hline \multicolumn{8}{|c|}{ 75RH-DOL (Top surface) } & & \\
\hline $\begin{array}{l}\text { Average Area } \\
\left(25 \mathrm{~mm}^{2}\right)\end{array}$ & $7.17 \pm 2.08$ & $7.21 \pm 1.95$ & -6.8 & $9.47 \pm 2.75$ & $9.52 \pm 2.72$ & 0.5 & $29.51 \pm 7.87$ & $29.85 \pm 7.41$ & \multirow[t]{2}{*}{1.1} \\
\hline Porous profile 1 & 9.68 & 11.98 & & 13.77 & 15.80 & & 36.45 & 42.29 & \\
\hline Porous profile 2 & 10.24 & 11.35 & 12.9 & 13.07 & 14.38 & 8.5 & 45.07 & 46.02 & 6.3 \\
\hline Porous profile 3 & 5.24 & 5.54 & & 7.26 & 7.07 & & 21.42 & 21.55 & \\
\hline $\begin{array}{l}\text { Non } \\
\text { porous profile } 4\end{array}$ & 3.07 & 2.73 & -12.5 & 3.96 & 3.52 & -12.5 & 9.85 & 9.38 & -5.0 \\
\hline \multicolumn{10}{|c|}{ 75RH-DOL (Bottom surface) } \\
\hline $\begin{array}{c}\text { Average Area } \\
\left(25 \mathrm{~mm}^{2}\right)\end{array}$ & $8.73 \pm 2.07$ & $8.57 \pm 2.19$ & -1.9 & $11.18 \pm 5.08$ & $10.99 \pm 2.75$ & -1.7 & $34.97 \pm 7.61$ & $34.11 \pm 7.67$ & -2.5 \\
\hline Porous profile 1 & 12.35 & 11.98 & -3.1 & 15.60 & 15.80 & 1.3 & 46.42 & 42.29 & -9.8 \\
\hline $\begin{array}{c}\text { Non } \\
\text { porous profile } 2\end{array}$ & 9.25 & 4.65 & -98.9 & 12.00 & 5.86 & -104.8 & 37.27 & 20.24 & -84.1 \\
\hline \multicolumn{10}{|c|}{ 33RH-DOL (Top surface) } \\
\hline $\begin{array}{l}\text { Average Area } \\
\quad\left(25 \mathrm{~mm}^{2}\right)\end{array}$ & $14.68 \pm 2.29$ & $6.93 \pm 1.76$ & -111.8 & $8.98 \pm 2.04$ & $9.05 \pm 2.33$ & 0.8 & $29.44 \pm 5.80$ & $29.66 \pm 6.59$ & 0.7 \\
\hline Porous profile 2 & 10.82 & 9.77 & 5.5 & 13.37 & 12.64 & -5.8 & 40.25 & 41.87 & 3.9 \\
\hline $\begin{array}{c}\text { Non porous } \\
\text { profile } 1\end{array}$ & 3.64 & 3.85 & -10.8 & 4.78 & 4.97 & 3.8 & 17.06 & 15.68 & -8.8 \\
\hline \multicolumn{10}{|c|}{ 33RH-DOL (Bottom surface) } \\
\hline $\begin{array}{l}\text { Average Area } \\
\left(25 \mathrm{~mm}^{2}\right)\end{array}$ & $6.31 \pm 1.71$ & $6.35 \pm 1.76$ & 0.6 & $8.37 \pm 2.55$ & $8.50 \pm 2.56$ & 1.5 & $26.89 \pm 6.79$ & $27.27 \pm 6.77$ & 1.4 \\
\hline Porous profile 1 & 6.49 & 6.22 & \multirow{2}{*}{-15.7} & 8.28 & 7.91 & \multirow{2}{*}{-14.3} & 28.93 & 29.63 & \multirow{2}{*}{-8.87} \\
\hline Porous profile 2 & 12.65 & 10.33 & & 15.74 & 13.11 & & 51.49 & 44.24 & \\
\hline $\begin{array}{c}\text { Non porous } \\
\text { profile } 3\end{array}$ & 6.04 & 5.18 & -16.6 & 7.24 & 6.54 & -10.7 & 25.98 & 21.93 & -18.5 \\
\hline
\end{tabular}


Table 3

\begin{tabular}{|c|c|c|c|c|c|c|c|c|c|}
\hline \multirow[t]{2}{*}{ Specimen } & \multicolumn{2}{|c|}{$\begin{array}{c}\text { X Axe } \\
(\mathrm{m} / \mathrm{s})\end{array}$} & \multicolumn{2}{|c|}{$\begin{array}{l}\text { Y Axe } \\
(\mathrm{m} / \mathrm{s})\end{array}$} & \multicolumn{2}{|c|}{$\begin{array}{c}\text { Z Axe } \\
(\mathrm{m} / \mathrm{s})\end{array}$} & \multicolumn{2}{|c|}{$\begin{array}{c}\text { Average } \\
\text { velocity } \\
\text { for } 3 \text { axes } \\
(\mathrm{m} / \mathrm{s})\end{array}$} & \multirow[t]{2}{*}{$\begin{array}{c}\text { Average } \\
\text { variation } \\
\text { velocity } \\
\Delta \mathrm{Vp}(\%)\end{array}$} \\
\hline & Before & After & Before & After & Before & After & Before & After & \\
\hline 75RH-DOL & 2291 & 2719 & 2075 & 2418 & 2197 & 2617 & 2187 & 2585 & 18 \\
\hline 33RH-DOL & 2795 & 2926 & 2424 & 2497 & 2804 & 2819 & 2674 & 2747 & 3 \\
\hline
\end{tabular}


Table 4

\begin{tabular}{|c|c|c|c|c|c|c|}
\hline \multirow[t]{2}{*}{ Specimen } & \multirow{2}{*}{$\begin{array}{c}\Delta \text { Water } \\
\text { absorption by } \\
\text { capillarity }(\%)\end{array}$} & \multicolumn{2}{|c|}{$\begin{array}{l}\text { Water absorption by } \\
\text { capillarity }(\mathrm{g})\end{array}$} & \multirow[t]{2}{*}{$\begin{array}{l}\nabla \text { Capillarity } \\
\text { coefficient }\end{array}$} & \multicolumn{2}{|c|}{$\begin{array}{l}\text { Capillarity } \\
\text { coefficient } \\
\left(\mathrm{g} / \mathrm{m}^{2} \cdot \mathrm{s}^{0.5}\right)\end{array}$} \\
\hline & & Before & After & & Before & After \\
\hline 75RH-DOL & 58 & 0.93 & 1.51 & -83 & 198.25 & 108.26 \\
\hline 33RH-DOL & 13 & 0.91 & 1.04 & -2 & 141.53 & 122.35 \\
\hline
\end{tabular}


Table 5

\begin{tabular}{|c|c|c|c|c|c|c|c|c|}
\hline \multirow[t]{2}{*}{ Specimen } & \multicolumn{2}{|c|}{$\begin{array}{l}\text { Apparent density } \\
\left(\mathrm{g} / \mathrm{cm}^{3}\right)\end{array}$} & \multirow{2}{*}{$\begin{array}{l}\nabla \text { saturation } \\
(\%)\end{array}$} & \multicolumn{2}{|c|}{$\begin{array}{l}\text { saturation } \\
(\%)\end{array}$} & \multirow{2}{*}{$\begin{array}{c}\nabla \text { Open } \\
\text { porosity } \\
(\%)\end{array}$} & \multicolumn{2}{|c|}{$\begin{array}{c}\text { Open porosity } \\
(\%)\end{array}$} \\
\hline & Before & After & & Before & After & & Before & After \\
\hline 75RH-DOL & 2.28 & 2.29 & -0.35 & 8.30 & 7.95 & -0.75 & 18.95 & 18.20 \\
\hline 33RH-DOL & 2.35 & 2.36 & -0.15 & 7.06 & 6.91 & -0.3 & 16.60 & 16.3 \\
\hline
\end{tabular}




\section{Table 6}

\begin{tabular}{|c|c|c|c|c|c|c|c|c|c|c|}
\hline \multirow{2}{*}{\multicolumn{2}{|c|}{ 75RH-DOL }} & \multicolumn{2}{|l|}{ Area 1} & \multirow[b]{2}{*}{$\begin{array}{l}\nabla / \Delta \\
(\%) \\
\end{array}$} & \multicolumn{2}{|l|}{ Area 2} & \multirow[b]{2}{*}{$\begin{array}{l}\nabla / \Delta \\
(\%) \\
\end{array}$} & \multicolumn{2}{|l|}{ Area 3} & \multirow[b]{2}{*}{$\begin{array}{l}\nabla / \Delta \\
(\%)\end{array}$} \\
\hline & & Before & After & & Before & After & & Before & After & \\
\hline \multirow{3}{*}{ के } & $\mathrm{T} 1$ (ms) & $501.3 \pm 25.5$ & $501.3 \pm 25.4$ & 0.00 & $421.2 \pm 36.5$ & $379.3 \pm 31.7$ & -11.03 & $351.2 \pm 24.9$ & $301.7 \pm 20.9$ & 16.38 \\
\hline & $\mathrm{T} 2(\mathrm{~ms})$ & $18.4 \pm 0.8$ & $16.5 \pm 0.8$ & -11.29 & $11.9 \pm 0.9$ & $10.0 \pm 0.7$ & -18.96 & $7.3 \pm 0.4$ & $6.1 \pm 0.3$ & 19.64 \\
\hline & $\mathrm{PD}(\mathrm{T} 2)$ & 998466.7 & 1328725.0 & 9.8 & 704889.7 & 913424.5 & 7.4 & 881687.3 & 1071636.5 & 1.3 \\
\hline \multirow{3}{*}{ 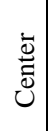 } & $\mathrm{T} 1(\mathrm{~ms})$ & $492.3 \pm 24.3$ & $472.1 \pm 25.9$ & -4.28 & $417.6 \pm 37.1$ & $394.3 \pm 30.5$ & -5.91 & $354.2 \pm 26.7$ & $333.8 \pm 24.4$ & -6.10 \\
\hline & $\mathrm{T} 2(\mathrm{~ms})$ & $18.9 \pm 0.8$ & $15.6 \pm 0.7$ & -21.26 & $11.4 \pm 0.8$ & $8.8 \pm 0.5$ & -29.95 & $8.0 \pm 0.5$ & $6.4 \pm 0.3$ & 25.35 \\
\hline & $\mathrm{PD}(\mathrm{T} 2)$ & 917109.2 & 1160287.8 & 5.1 & 718961.7 & 1017069.2 & 15.2 & 837415.3 & 1085073.7 & 7.4 \\
\hline \multirow{3}{*}{ 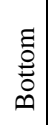 } & $\mathrm{T} 1$ (ms) & $441.7 \pm 28.1$ & $456.6 \pm 30.0$ & 3.25 & $411.7 \pm 34.6$ & $412.2 \pm 35.9$ & 0.14 & $331.5 \pm 23.7$ & $329.6 \pm 25.5$ & -0.59 \\
\hline & $\mathrm{T} 2(\mathrm{~ms})$ & $16.6 \pm 0.9$ & $17.2 \pm 0.8$ & 3.26 & $10.9 \pm 0.7$ & $10.7 \pm 0.7$ & -1.88 & $7.0 \pm 0.40$ & $7.0 \pm 0.4$ & 0.65 \\
\hline & $\mathrm{PD}(\mathrm{T} 2)$ & 763803.83 & 1021012.3 & 10.2 & 738198.5 & 929794.5 & 4.7 & 765598.8 & 935957.0 & 20.7 \\
\hline
\end{tabular}


Table 7

\begin{tabular}{|c|c|c|c|c|c|c|c|c|c|c|}
\hline \multirow{2}{*}{\multicolumn{2}{|c|}{ 33RH-DOL }} & \multicolumn{2}{|l|}{ Area 1} & \multirow[b]{2}{*}{$\begin{array}{l}\nabla / \Delta \\
(\%)\end{array}$} & \multicolumn{2}{|l|}{ Area 2} & \multirow[b]{2}{*}{$\begin{array}{l}\nabla / \Delta \\
(\%)\end{array}$} & \multicolumn{2}{|l|}{ Area 3} & \multirow[b]{2}{*}{$\begin{array}{l}\nabla / \Delta \\
(\%)\end{array}$} \\
\hline & & Before & After & & Before & After & & Before & After & \\
\hline \multirow{3}{*}{$\stackrel{8}{0}$} & $\mathrm{~T} 1$ (ms) & $237.2 \pm 18.1$ & $220.8 \pm 14.0$ & -7.43 & $291.5 \pm 22.4$ & $281.2 \pm 16.8$ & -3.67 & $346.7 \pm 30.2$ & $317.7 \pm 26.4$ & -9.14 \\
\hline & $\mathrm{T} 2(\mathrm{~ms})$ & $5.5 \pm 0.4$ & $6.1 \pm 0.5$ & 9.69 & $7.2 \pm 0.5$ & $6.4 \pm 0.4$ & -12.06 & $9.6 \pm 0.7$ & $7.7 \pm 0.4$ & -24.61 \\
\hline & $\mathrm{PD}(\mathrm{T} 2)$ & 901411.8 & 983566.7 & -2.60 & 1000383.5 & 1174487.0 & 4.6 & 855908.3 & 1021866.8 & 6.2 \\
\hline \multirow{3}{*}{ 离 } & $\mathrm{T} 1(\mathrm{~ms})$ & $244.7 \pm 19.6$ & $223.7 \pm 14.4$ & -9.37 & $292.3 \pm 21.4$ & $263.8 \pm 17.1$ & -10.81 & $324.8 \pm 28.9$ & $309.8 \pm 24.4$ & -4.82 \\
\hline & $\mathrm{T} 2(\mathrm{~ms})$ & $5.5 \pm 0.4$ & $4.9 \pm 0.3$ & -13.86 & $6.4 \pm 0.4$ & $5.1 \pm 0.3$ & -24.48 & $8.3 \pm 0.6$ & $6.7 \pm 0.4$ & -24.87 \\
\hline & $\mathrm{PD}(\mathrm{T} 2)$ & 840444.5 & 977742.2 & 3.7 & 964283.5 & 1217553.5 & 11.3 & 818962.7 & 1035710.2 & 11.4 \\
\hline \multirow{3}{*}{$\begin{array}{l}\Xi \\
0 \\
0 \\
0 \\
0\end{array}$} & $\mathrm{~T} 1(\mathrm{~ms})$ & $234.4 \pm 19.7$ & $231.3 \pm 16.5$ & -1.37 & $273.6 \pm 22.4$ & $268.5 \pm 19.0$ & -1.92 & $304.1 \pm 22.7$ & $287.0 \pm 21.3$ & -5.95 \\
\hline & $\mathrm{T} 2(\mathrm{~ms})$ & $5.7 \pm 0.4$ & $5.5 \pm 0.4$ & -2.55 & $6.7 \pm 0.5$ & $5.8 \pm 0.3$ & -15.28 & $7.2 \pm 0.5$ & $6.4 \pm 0.4$ & -13.10 \\
\hline & $\mathrm{PD}(\mathrm{T} 2)$ & 723004.7 & 841952.7 & 3.8 & 797009.2 & 1017586.7 & 12.3 & 852742.8 & 982940.5 & 2.8 \\
\hline
\end{tabular}

